\title{
Disaster Risk and Preference Shifts in a New Keynesian Model
}

\author{
Marlène Isoré \& Urszula Szczerbowicz
}

\section{Highlights}

- A time-varying probability of 'disaster' is sufficient to generate a recession and an increase in risk premia in the literature.

- However, this result critically relies on the value of the elasticity of intertemporal substitution (EIS). Indeed, when the EIS is smaller than unity, the agents choose to save and invest more. In a real business cycle model, an increase in disaster risk thus creates a boom.

- The New Keynesian structure allows to conciliate the recessionary effects of disaster risk with a plausible value of the EIS through the sluggishness in price adjustments.

- The model then generates recession and deflation, as well as a decrease in consumption, investment and wages, in line with the preference shock literature, while it preserves the countercyclicality of risk premia. 


\section{Abstract}

This paper analyzes the effects of a change in a small but time-varying "disaster risk" à la Gourio (2012) in a New Keynesian model. Real business cycle models featuring disaster risk have been successful in replicating observed moments of equity premia, yet their macroeconomic responses are highly sensitive to the chosen value of the elasticity of intertemporal substitution (EIS). In particular, we show here that an increase in the probability of disaster causes a recession only when imposing an EIS larger than unity, which may be arbitrarily large. Nevertheless, we also find that incorporating sticky prices allows to conciliate recessionary effects of the disaster risk with a plausible value of the EIS. The disaster risk shock causes endogenous shifts in preferences which provide a rationale for discount factor first- (Christiano et al., 2011) and second- (Basu and Bundick, 2014) moment shocks.

\section{Keywords}

Disaster risk, Rare events, Uncertainty, Asset pricing, DSGE models, New Keynesian models, Business cycles.

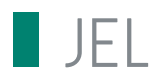

D81, D90, E20, E31, E32, E44, G12, Q54.

\section{Working Paper}

\section{CEPI}

CEPII (Centre d'Etudes Prospectives et d'Informations Internationales) is a French institute dedicated to producing independent, policyoriented economic research helpful to understand the international economic environment and challenges in the areas of trade policy, competitiveness, macroeconomics, international finance and growth
CEPII Working Paper

Contributing to research in international economics

C C CEPII, PARIS, 2015

All rights reserved. Opinions expressed in this publication are those of the author(s) alone.

$\begin{array}{ll}\text { Editorial Director: } & \text { CEPII } \\ \text { Sébastien Jean } & \begin{array}{l}113, \text { rue de Grenelle } \\ 75007 \text { Paris }\end{array} \\ \text { Production: } & +33153685500 \\ \text { Laure Boivin } & \text { www.cepii.fr } \\ \text { No ISSN: } 1293-2574 & \text { Press contact: presse@ }\end{array}$




\title{
Disaster Risk and Preference Shifts in a New Keynesian Model ${ }^{1}$
}

\author{
Marlène Isoré* and Urszula Szczerbowicz ${ }^{\dagger}$
}

\section{Introduction}

In the recent years, interest in the economic impact of 'rare events' has been renewed. In particular, Gabaix (2011, 2012) and Gourio (2012) have introduced in real business cycle models a small but time-varying probability of 'disaster', defined as an event that destroys a large share of the existing capital stock and productivity. The key feature is that an increase in the probability of disaster, without occurrence of the disaster itself, suffices to trigger a recession and replicate some asset pricing regularities.

However, these effects crucially rely on the assumption of an intertemporal elasticity of intertemporal substitution (EIS) being greater than unity. In Gourio (2012), an unexpected increase in the probability of disaster is equivalent, under some assumptions, to a decrease in agents' discount factor, i.e in their degree of patience. Agents then save and invest less, as they prefer to increase current consumption. In the RBC setup, this in turn causes a recession and an increase in risk premia. Yet, this initial response of the discount factor holds only under the assumption of an EIS larger than unity. Indeed, as known since Leland (1968) and Sandmo (1970), an increase in interest rate risk increases agents' propensity to consume, and thus reduce savings, if and only if the EIS is larger than 1 . On the contrary, when the EIS is low, income effects overcome substitution effects and savings go up. ${ }^{2}$ This implies that Gourio (2012)'s predictions would not hold for values of the EIS smaller than unity. Indeed, savings would then increase with disaster risk, surprisingly driving the economy into a boom. Although still under debate, an EIS below unity is yet empirically plausible, and macroeconomic mod-

\footnotetext{
${ }^{1}$ We thank George-Marios Angeletos, Guido Ascari, Pierpaolo Benigno, Nick Bloom, Luca Dedola, Martin Ellison, Xavier Gabaix, François Gourio, Sébastien Jean, Vivien Lewis, Julien Matheron, Antonio Mele, Salvatore Nisticò, Juan Carlos Parra-Alvarez, Antti Ripatti, Kjetil Storesletten, Fabien Tripier, Natacha Valla, Philippe Weil, Raf Wouters, and Francesco Zanetti, as well as numerous participants at Bank of Finland, Bank of Norway, CEPII, KU Leuven's International Economics seminar, the IIBEO workshop, and Oxford's Macroeconomics group, for fruitful discussions at different stages of this work. We are grateful to the Yrjo Jahnsson Foundation for financial support.

*University of Helsinki, HECER (marlene.isore@helsinki.fi)

†CEPII (urszula.szczerbowicz@cepii.fr)

${ }^{2}$ Weil (1990) shows that a large EIS implies that the elasticity of savings to a 'certainty-equivalent' interest rate is positive, i.e savings decrease in the aggregate interest rate risk. On the contrary, a small EIS implies that savings go up with interest rate risk.
} 
els have largely adopted this range as conventional in their calibration, whether they feature Epstein-Zin-Weil preferences or not. ${ }^{3}$

This paper introduces a small time-varying probability of disaster à la Gourio (2012) into a New Keynesian model. To the best of our knowledge, we are the first to do so. ${ }^{4}$ The contribution is threefold. First, we aim at shedding some light on the critical role of the EIS in driving the disaster risk results. In particular, we are here able to nest Gourio (2012)'s mechanism in a decentralized flexible-price economy and show that they generate a boom with any EIS below unity. Second, we show that introducing sticky prices provide a simple solution to this puzzle. Indeed, we show that recessionary effects of disaster risk can be conciliated with an EIS below unity, and thus offer a framework that restores and generalizes Gourio (2012)'s predictions. Third, our endogenous increase in the discount factor from disaster risk is highly reminiscent of two other types of shocks in the literature: $(i)$ exogenous 'preference shocks' defined as shocks to the level of the discount factor (Smets and Wouters, 2003, Christiano et al., 2011), and (ii) 'uncertainty shocks' defined as shocks to the volatility of the discount factor (Basu and Bundick, 2014). This suggests that disaster risk may give a rationale to firstand second-moment preference shocks in the literature.

Developing a full-fleshed New Keynesian model is critical here, not just in order to create a richer macroeconomic setting and broaden the spectrum of potential policy analysis, but because it literally conditions most of the macroeconomic effects associated with a change in the disaster risk, for a given EIS. The reason for that is particularly intuitive. Consider for instance a low EIS, in which case the discount factor goes up with the probability of disaster, such that agents do choose to save more. In a flexible-price setup, the economy is mostly driven by this supply-side effect: savings and therefore investment increase due to precautionary motives, as well as does the labor supply, such that the economy enters a boom. In contrast, sticky prices make the output fluctuations more sensitive to the demand-side effect of the shock: lower current consumption drives the recession. Despite higher savings, investment also decreases as firms' demand for production factors goes down. Hence, the sticky vs flexible price setup totally changes the macroeconomic dynamics caused by the disaster risk shock, for a given value of the EIS. In the same spirit, Basu and Bundick (2014) show that the economy responds differently to uncertainty shocks under sticky versus flexible prices. In

\footnotetext{
${ }^{3}$ See Section 5.2 about evidence and calibration of the EIS in the literature.

${ }^{4}$ Two working papers previously attempted to introduce disaster risk in a New Keynesian setup, yet handling it in very narrowed ways: Isoré and Szczerbowicz (2013) reduce the disaster risk to its capital depreciation channel only, while Brede (2013) considers the disaster state to be permanent and deterministic, i.e the economy entering a disaster state happens to stay there forever. As far as we know, our current paper is thus the first one that keeps the essence of disaster risk as a time-varying source of uncertainty, in the spirit of Gourio (2012), in a New Keynesian model.
} 
particular, they show that positive co-movements between consumption and investment, as oberserved in the data, are generated in the sticky-price case only. Our results are aligned with this analysis and suggest that a time-varying disaster risk à la Gourio (2012) can provide a rationale for second-moment preference shocks, once accounting for the critical role of the EIS. Another interesting finding is that the depressed consumption, stemming from the rise in disaster risk in the sticky prices version only, also causes deflation and lowers firms' demand for production factors (and thus a downside effect on wages), along with the recession and a rise in the risk premium. This seems to be particularly consistent with the literature considering shocks to the level of the discount factor as a potential source of zero-lower bound on nominal interest rates (e.g Christiano et al., 2011).

The remainder of this paper is as follows. Section 2 presents the model. Section 3 gives the calibration values and discusses the steady-state, in particular whether Tallarini (2000)'s "observational equivalence" holds or not when the disaster risk is present in the economy. Section 4 shows the responses to an unexpected increase in the disaster risk. Gourio (2012)'s results are nested when prices are flexible and the EIS is larger than 1 , while reversed when the EIS is smaller than 1 . Then, with sticky prices and an EIS smaller than 1, we find that the disaster risk causes a recession, deflation, and increase in the risk premium in particular. Section 5 reviews the literature and further discusses the soundness of our results. Section 6 concludes.

\section{Model}

\subsection{Households}

\subsubsection{The household problem with disasters}

Let us consider households with Epstein-Zin-Weil preferences given by

$$
\tilde{V}_{t}=\left[\left[C_{t}\left(1-L_{t}\right)^{\varpi}\right]^{1-\psi}+\beta_{0}\left(E_{t} \tilde{V}_{t+1}^{1-\gamma}\right)^{\frac{1-\psi}{1-\gamma}}\right]^{\frac{1}{1-\psi}}
$$

where $C$ is consumption, $L$ labor supply, $\gamma$ the coefficient of risk aversion, and $1 / \tilde{\psi}$ the elasticity of intertemporal substitution (EIS) with $\tilde{\psi}=1-(1+\varpi)(1-\psi)$. Households' capital accumulates as

$$
K_{t+1}=\left[\left(1-\delta_{0} u_{t}^{\eta}\right) K_{t}+S\left(\frac{I_{t}}{K_{t}}\right) K_{t}\right] e^{x_{t+1} \ln (1-\Delta)}
$$


where $K$ stands for capital, $I$ investment, $u$ variable utilization rate of capital, $S($.$) convex$ capital adjustment costs (with specific form given further below). In addition, $x$ is an indicator variable capturing the occurrence of a "disaster" destroying a large share of the existing capital stock. Specifically, there is a time-varying probability $\theta_{t}$ that a disaster occurs in the next period, $x_{t+1}=1$, in which case a share $\Delta$ of capital is destroyed. Otherwise, $x_{t+1}=0$ and the capital accumulation law of motion is in line with standard New Keynesian models. Moreover, the probability of disaster, $\theta$, itself follows a first-order autoregressive process as

$$
\log \theta_{t}=\left(1-\rho_{\theta}\right) \log \bar{\theta}+\rho_{\theta} \log \theta_{t-1}+\sigma_{\theta} \varepsilon_{\theta_{t}}
$$

where $\bar{\theta}$ is the mean disaster risk, $\rho_{\theta}$ the persistence, and $\varepsilon_{\theta}$ i.i.d innovations. ${ }^{5}$

In addition, households can buy one-period bonds issued by a public authority. As Gabaix (2012) and Gourio (2013), we assume that bonds are also subject to the disaster risk. Sovereign debt can indeed be risky during tail events in the sense that it becomes subject to partial default, as we have observed for Greece in the last financial crisis, Argentina in the early 2000s, or UK and US in the Great Depression, as for a few examples. Conditional on no disaster, bonds are however riskfree, unlike capital. It is worth mentioning that, following Gourio (2012)'s approach, we assume that the destruction share in case of a disaster, $\Delta$, is the same for the assets (both capital and bonds here) and productivity. Although this may appear as a strong assumption, this is essentially a trick used to solve the model with perturbation methods: when detrended by productivity, the system will then not be directly impacted by the large disaster event $(x)$ itself but only by the small probability of disaster $(\theta)$, which is our variable of interest. ${ }^{6}$

Finally, households rent their capital and labor force to monopolistic competition firms. They own these firms, hence earn profits. They pay lump-sum taxes to the public authority. Thus, their budget constraint is

$$
C_{t}+I_{t}+\frac{B_{t+1}}{p_{t}}+T_{t} \leq \frac{W_{t}}{p_{t}} L_{t}+\frac{B_{t}\left(1+r_{t-1}\right)}{p_{t}} e^{x_{t+1} \ln (1-\Delta)}+\frac{P_{t}^{k}}{p_{t}} u_{t} K_{t}+D_{t}
$$

\footnotetext{
${ }^{5}$ These parameters are calibrated according to empirical estimations of disaster risk (Section 3). Our qualitative results are yet essentially insensitive to these values, including when persistence in disaster risk is nil (Section 4.2). Also, although nothing technically prevents the probability of disaster to exceed unity with perturbation methods (featuring normally distributed innovations), the calibrated mean and variance are so low that this is extremely unlikely. In our impulse analysis (Section 4.1), the bound is clearly not met.

${ }^{6}$ It is possible to release this constraint by using projection methods to solve the model, as Gourio (2012) also does with a smaller set of variables. Another alternative would be to make an assumption on whether the economy is currently in a disaster state, $x=1$, or not $x=0$, when generating the impulse response functions for the disaster risk, $\theta$.
} 
where $W$ denotes the (nominal) wage rate, $p$ the good price, $B$ the bonds and $r$ the corresponding interest rate, $P_{t}^{k}$ is the (nominal) rental rate of capital, $u$ the utilization rate of capital, $I$ the investment, $T$ the taxes, and $D$ the (real) dividends from monopolistic firms' (real) profits.

The households want to maximize utility subject to their capital accumulation and the budget constraints. However, because the indicator variable is present in this optimization problem and thus in the equilibrium condition, we cannot directly use the perturbation methods to solve the model as such. Therefore, we follow Gourio (2012) in detrending the system such that the disaster risk only, and not the disaster event, impacts the detrended system.

\subsubsection{Detrending the household's problem}

Let us thus assume, as in Gabaix (2012) and Gourio (2012), that productivity, denoted z, is also partly destroyed in case of a disaster, and follows

$$
\frac{z_{t+1}}{z_{t}}=e^{\mu+\varepsilon_{z, t+1}+x_{t+1} \ln (1-\Delta)}
$$

where $\mu$ is a trend and $\varepsilon_{z, t+1}$ i.i.d normally distributed innovations with zero mean. ${ }^{7}$ As mentioned above, assuming that the share $\Delta$ is the same as for the physical assets, the detrended variables will not depend on the disaster event anymore, but will still be affected by the disaster risk. In particular, the household's budget constraint in detrended terms reads as

$$
c_{t}+i_{t}+\frac{b_{t+1}}{p_{t}} e^{\mu+\varepsilon_{z, t+1}}+\frac{T_{t}}{z_{t}} \leq \frac{w_{t}}{p_{t}} L_{t}+\frac{b_{t}\left(1+r_{t-1}\right)}{p_{t}}+\frac{P_{t}^{k}}{p_{t}} u_{t} k_{t}+\frac{D_{t}}{z_{t}}
$$

while the capital accumulation becomes

$$
k_{t+1}=\frac{\left(1-\delta_{t}\right) k_{t}+S\left(\frac{i_{t}}{k_{t}}\right) k_{t}}{e^{\mu+\varepsilon_{z, t+1}}}
$$

where lower case letters denote the detrended variables $\left(k_{t}=K_{t} / z_{t}\right.$, etc), and where, in line with the New Keynesian literature, the capital depreciation rate is considered as a function of the capital utilization rate

$$
\delta_{t}=\delta_{0} u_{t}^{\eta}
$$

\footnotetext{
${ }^{7}$ Labor productivity may indeed decrease during financial crises (e.g Hughes and Saleheen, 2012), as well as during wars or natural disasters as people may find themselves not necessarily matched with jobs requiring their specific skills. Total factor productivity may also decrease as firms facing severe financing constraints may reduce their R\&D expenditures (Millard and Nicolae, 2014).
} 
while the capital adjustment cost function, with usual properties, reads as

$$
S\left(\frac{i_{t}}{k_{t}}\right)=\frac{i_{t}}{k_{t}}-\frac{\tau}{2}\left(\frac{i_{t}}{k_{t}}-\frac{\bar{i}}{\bar{k}}\right)^{2}
$$

Note that indeed, the disaster indicator $x_{t+1}$ finds itself canceled out from this part of the model. Then, as far as objective function is concerned, let us define $v_{t}=\frac{V_{t}}{z_{t}^{1-\psi}}$, with $\tilde{V}_{t}=$ $V_{t}^{\frac{1}{1-\psi}}$, such that we get

$$
v_{t}=\left[c_{t}\left(1-L_{t}\right)^{\varpi}\right]^{1-\psi}+\beta\left(\theta_{t}\right) e^{(1-\psi) \mu}\left[E_{t} e^{(1-\gamma) \varepsilon_{z, t+1}} v_{t+1}^{1-\chi}\right]^{\frac{1}{1-\chi}}
$$

where $\chi=1-\frac{1-\gamma}{1-\psi}$ is a combination of parameters, and where the discount factor becomes a function of the time-varying disaster risk as given by

$$
\beta(\theta)=\beta_{0}\left[1-\theta_{t}+\theta_{t} e^{(1-\gamma) \ln (1-\Delta)}\right]^{\frac{1-\psi}{1-\gamma}}
$$

which is similar to Gourio (2012)'s expression. ${ }^{8}$ The households will thus maximize (5) subject to (1)-(4) and (6). ${ }^{9}$

The beauty of Gourio (2012)'s detrending approach is that the probability of disaster risk, $\theta$, now appears in this endogenous discount factor only. Therefore, an unexpected change in disaster risk will drive macroeconomic quantities and asset prices responses through a combination of first- and second-moment effects on the discount factor. ${ }^{10}$ In that respect, it is expected to resemble both 'preference shocks' (in level) à la Smets and Wouters (2003) and Christiano et al. (2011) and second-moment preference shocks ('uncertainty shocks') à la Basu and Bundick (2014).

A closer look at equation (6) above makes it clear that the value of the EIS determines the sign of the effect of the probability of disaster $(\theta)$ on the discount factor, and thus agents' propensity to save or consume in response to such a shock. In particular, agents become more patient (higher $\beta(\theta)$ ) whenever the EIS is below unity, and on the contrary, more impatient (lower $\beta(\theta)$ ) for all values of the EIS larger than unity. Note that this holds for all degrees of risk aversion, including risk neutrality. ${ }^{11}$ In the specific case where the EIS is exactly equal

\footnotetext{
${ }^{8}$ Gourio (2012) also makes the size of the disaster, $\Delta$, a random variable. We consider it constant here for the sake of simplicity, but could easily introduce this feature as well.

${ }^{9}$ The first-order conditions and calculation details are provided in Appendix.

${ }^{10}$ See the last paragraph on page 13 of Gourio (2012) for more about this.

${ }^{11}$ Rewriting $(6)$ as $\beta(\theta)=\beta_{0}\left[1-\theta_{t}\left(1-e^{(1-\gamma) \ln (1-\Delta)}\right)\right]^{\frac{1-\gamma / E I S}{(1-\gamma)(1+\infty)}}$ and taking the derivative with respect to $\theta$, it is the case that $\partial \beta(\theta) / \partial \theta$ is positive (respectively, negative) for any EIS smaller (respectively larger) than one. This holds for all degrees of risk aversion (including risk neutrality), i.e $\forall \gamma \geq 0$. See more about this in Appendix.
} 
to unity, $\beta(\theta)$ boils down to $\beta_{0}$, i.e the probability of disaster does not have any impact on the macroeconomic quantities, but only on asset pricing. Thus, here as in Gourio (2012), the so-called 'Tallarini (2000)'s equivalence', i.e the quantities being determined irrespectively of the level of aggregate risk or risk aversion, holds if and only if EIS $=1$.

In the partial equilibrium built so far, the sign of the preference shift in response to the disaster risk shock suffices to determine the sign of the output variation: an increase in the probability of disaster causes a recession when the EIS is larger than one, a boom otherwise. Intuitively, higher impatience makes agents save less, thus invest less, such that the output falls. Yet, an EIS smaller than unity is empirically sound, and it seems surprising that disaster risk is positively correlated with output in that case. This is the puzzle we solve here in general equilibrium by introducing sticky prices. The nominal rigidity does not alter the relationship between the value of the EIS and the sign of the preference shift discussed above. However, it makes output respond primarily to consumption rather than savings, and thus allows to conciliate recessionary effects of the disaster risk with an EIS lower than unity. ${ }^{12}$

\subsubsection{The stochastic discount factor}

The (real) stochastic discount factor is defined under Epstein-Zin preferences as $Q_{t, t+1} \equiv$ $\frac{\partial \tilde{V}_{t} / \partial C_{t+1}}{\partial \tilde{V}_{t} / \partial C_{t}}$. For the non detrended model, this gives us

$$
Q_{t, t+1}=\beta_{0}\left(\frac{C_{t+1}}{C_{t}}\right)^{-\psi}\left(\frac{1-L_{t+1}}{1-L_{t}}\right)^{\varpi(1-\psi)} \frac{V_{t+1}^{-\chi}}{\left(E_{t} V_{t+1}^{1-\chi}\right)^{\frac{-\chi}{1-\chi}}}
$$

which is identical to Gourio (2012)'s, and from the detrended terms

$$
Q_{t, t+1}=\frac{z_{t}}{z_{t+1}}\left(\frac{c_{t+1}}{c_{t}}\right)^{-\psi}\left(\frac{1-L_{t+1}}{1-L_{t}}\right)^{\varpi(1-\psi)} \beta\left(\theta_{t}\right) e^{(1-\psi) \mu} \frac{e^{(1-\gamma) \varepsilon_{z, t+1}} v_{t+1}^{-\chi}}{\left[E_{t} e^{(1-\gamma) \varepsilon_{z, t+1}} v_{t+1}^{1-\chi}\right]^{\frac{-\chi}{1-\chi}}}
$$

Since the disaster event $(x)$ is present within the productivity growth term here, we also need to define a "detrended" stochastic discount factor as $\tilde{Q}_{t, t+1} \equiv \frac{z_{t+1}}{z_{t}} Q_{t, t+1}$ that we can use, together with the first-order condition on bonds so as to solve for the macroeconomic

\footnotetext{
${ }^{12}$ It can be the case that some other model specifications allow for the same results. In particular, a real business cycle model with price determinacy for some periods or a simpler New Keynesian model without capital could potentially reach the same conclusions.
} 
quantities

$$
E_{t} \tilde{Q}_{t, t+1}=E_{t}\left(\frac{1+\pi_{t+1}}{1+r_{t}} e^{\mu+\varepsilon_{z, t+1}}\right)
$$

For determining the asset prices in the following subsection, we however still use the proper stochastic discount factor as given by

$$
E_{t} Q_{t, t+1}=E_{t}\left(\frac{1+\pi_{t+1}}{1+r_{t}} \frac{1}{e^{x_{t+1} \ln (1-\Delta)}}\right)
$$

\subsubsection{The risk premium}

From asset pricing orthogonality condition we can define the following rates

(i) The riskfree rate, $R^{f}$, is obtained from

$$
E_{t}\left[Q_{t, t+1} R_{t+1}^{f}\right]=1
$$

Note that this is not the yield on bonds, which are only riskfree conditional on no disaster here, but rather a "natural" (gross) interest rate.

(ii) the (real) rate of return on capital $R_{t+1}^{k, \text { real }}$, from $E_{t}\left[Q_{t, t+1} R_{t+1}^{k, \text { real }}\right]=1$, which can be rewritten, replacing $Q_{t, t+1}$ from equation (8), as

$$
R_{t+1}^{k, r e a l}=\frac{z_{t+1}}{z_{t}} \frac{1}{e^{\mu+\varepsilon_{z, t+1}}} \frac{1+r_{t}}{1+\pi_{t+1}}=e^{x_{t+1} \ln (1-\Delta)} \frac{1+r_{t}}{1+\pi_{t+1}}
$$

Using the first-order condition on capital and non-detrended terms, we get

$$
\begin{gathered}
R_{t+1}^{k, r e a l}=e^{x_{t+1} \ln (1-\Delta)}\left\{\frac{P_{t+1}^{k}}{p_{t+1}} \frac{u_{t+1}}{q_{t}}+\frac{q_{t+1}}{q_{t}}\left[1-\delta_{0} u_{t+1}^{\eta}+\tau \frac{i_{t+1}}{k_{t+1}}\left(\frac{i_{t+1}}{k_{t+1}}-\frac{\bar{i}}{\bar{k}}\right)\right.\right. \\
\left.\left.-\frac{\tau}{2}\left(\frac{i_{t+1}}{k_{t+1}}-\frac{\bar{i}}{\bar{k}}\right)^{2}\right]\right\}
\end{gathered}
$$

which reminds both Gourio (2012)'s centralized economy version, as the disaster event directly affects the return on capital, and the expression in DSGE models in the absence of disaster risk (e.g Benigno and Paciello, 2014). 
(iii) The risk premium of holding capital is defined, in gross terms, as the ratio of the real return on capital $(i i)$ to the riskfree rate $(i)$, i.e

$$
E_{t}\left(\text { Risk premium }_{t+1}\right) \equiv E_{t}\left(R_{t+1}^{k, r e a l} / R_{t+1}^{f}\right)
$$

Note that the risk premium is nil in a first-order approximation, constant in the second order, and time-varying in the third and higher orders.

The value of the EIS has a partial equilibrium effect on the responses of these asset returns to the disaster risk shock. In order to better understand it, let us have a look at the expression of these asset returns in the balanced growth path of our economy. First, the stochastic discount factor is

$$
Q\left(x^{\prime}\right)=\beta_{0} \frac{e^{-\psi \mu-\gamma x^{\prime} \ln (1-\Delta)}}{\left(E e^{(1-\gamma) x^{\prime} \ln (1-\Delta)}\right)^{\frac{\psi-\gamma}{1-\gamma}}}
$$

which is a function of the disaster state, $x$. From the orthogonality condition $E\left(M\left(x^{\prime}\right) R^{k}\left(x^{\prime}\right)\right)=$ 1 , the return on capital is

$$
E\left(R^{k}\left(x^{\prime}\right)\right)=\frac{E\left(e^{x^{\prime} \ln (1-\Delta)}\right)}{\beta_{0} e^{-\psi \mu}\left(E e^{(1-\gamma) x^{\prime} \ln (1-\Delta)}\right)^{\frac{1-\psi}{1-\gamma}}}
$$

The riskfree rate is constant such that the corresponding asset pricing condition is $R^{f}=$ $1 / E\left(M\left(x^{\prime}\right)\right)$, which gives

$$
R^{f}=\frac{\left(E e^{(1-\gamma) x^{\prime} \ln (1-\Delta)}\right)^{\frac{\psi-\gamma}{1-\gamma}}}{\beta_{0} e^{-\psi \mu} E\left(e^{-\gamma x^{\prime} \ln (1-\Delta)}\right)}
$$

Note that the riskfree rate decreases in the disaster risk (along the balanced growth path), and the smaller the EIS, the larger the drop. ${ }^{13}$ This results is well known in the literature and often justifies the need for a use of an EIS larger than unity in order to limit the fall in the riskfree rate (Tsai and Watcher (2015). ${ }^{14}$ However, in our general equilibrium setup, the

\footnotetext{
${ }^{13}$ See the Appendix for calculation details.

${ }^{14} \mathrm{An}$ increase in disaster risk directly reduces the price of equities as it lowers expected cash flows. But meanwhile, it causes an increase in precautionary savings which diminishes the risk-free rate, and in turn tends to increase the price of equities by increasing demand relatively to the supply of equities. Whether this latter effect offsets the former depends on the value of EIS. Indeed, the smaller the EIS, the larger the precautionary savings and the drop in the risk free rate. For example, Berkman et al. (2011) show that the probability of disasters, defined as political crises, is negatively correlated with stock prices. Evidence of this kind encouraged the asset pricing literature to adopt an EIS larger than one.
} 
nominal rigidity modifies the effect of the EIS: the drop in the riskfree rate is then larger when the EIS is above unity. Asset pricing effects of the disaster risk can thus be restored with an EIS smaller than unity.

Finally, the risk premium along the balanced growth path is given by

$$
\frac{E\left(R^{k}\left(x^{\prime}\right)\right)}{R^{f}}=\frac{E\left(e^{x^{\prime} \ln (1-\Delta)}\right) E\left(e^{-\gamma x^{\prime} \ln (1-\Delta)}\right)}{E\left(e^{(1-\gamma) x^{\prime} \ln (1-\Delta)}\right)}
$$

As expected, the risk premium depends positively on the disaster risk, and the larger the risk aversion, the larger the effect. If agents were risk neutral, i.e when $\gamma=0$, the risk premium is unaffected by changes in the probability of disaster. Note that the EIS does not directly impact the value of the risk premium along the balanced growth path, in line with Gourio (2012). ${ }^{15}$ However, in the general equilibrium, the EIS will affect the responses of the risk premium to the disaster risk shock (See Section 4).

\subsection{Firms}

The structure of production considered here is quite standard as for a New Keynesian model. However, it plays crucial role for our results: unlike Gourio (2012)'s centralized economy flexible-price model, the decentralized economy featuring monopolistic competition and sticky prices allows to obtain recessionary effects from a disaster risk shock when the EIS is smaller than unity. The nominal price friction makes the reponse of output affected mostly by the demand side (consumption) rather than the supply side (savings) of the economy. Thus, the drop in consumption associated with a rise in disaster risk when the EIS is below unity will generate here recession and deflation.

Firms are operating in two sectors, final good production and intermediate good production. The former market is competitive, while the latter is monopolistic. They are briefly described below, see Appendix for details.

\subsubsection{Final good production}

The final good is an aggregate of intermediate goods $j$ as given by

$$
Y_{t}=\left(\int_{0}^{1} Y_{j, t}^{\frac{\nu-1}{\nu}} d j\right)^{\frac{\nu}{\nu-1}}
$$

${ }^{15}$ Gourio (2012) finds the same expression for the risk premium along the balanced growth path (Proposition 5). However, general equilibrium effects will differ here. 
where $\nu$ is the elasticity of substitution among intermediate goods. Profit maximization gives a demand curve which is decreasing in the price of intermediate good $j$ relative to the aggregate price index $\left(p_{j, t} / p_{t}\right)$ as

$$
Y_{j, t}=\left(\frac{p_{j, t}}{p_{t}}\right)^{-\nu} Y_{t}
$$

\subsubsection{Intermediate sector}

Intermediate sector firms use households' capital and labor to produce goods $j$, according to a Cobb-Douglas function with labor-augmenting productivity. In each period, they optimize the quantities of factors they want to use, taking their prices as given, subject to the production function and the aggregate demand function at a given output price. Thet also set their price optimally at frequency determined by a constant Calvo probability. ${ }^{16}$

The intra-temporal problem (cost minimization problem) is thus

$$
\begin{gathered}
\min _{L_{j, t}, \tilde{K}_{j, t}} W_{t} L_{j, t}+P_{t}^{k} \tilde{K}_{j, t} \\
\text { s.t. } \quad \tilde{K}_{j, t}^{\alpha}\left(z_{t} L_{j, t}\right)^{1-\alpha} \geq\left(\frac{p_{j, t}}{p_{t}}\right)^{-\nu} Y_{t}
\end{gathered}
$$

where $W_{t}^{n o m}$ is the (non-detrended) nominal wage rate and $P_{t}^{k}$ the capital rental rate. The first-order conditions, expressed in detrended terms, are

$$
\begin{gathered}
\left(L_{j, t}:\right) \quad w_{t}=m c_{j, t}^{n o m}(1-\alpha)\left(\frac{\tilde{k}_{j, t}}{L_{j, t}}\right)^{\alpha} \\
\left(\tilde{K}_{j, t}:\right) \quad P_{t}^{k}=m c_{j, t}^{n o m} \alpha\left(\frac{\tilde{k}_{j, t}}{L_{j, t}}\right)^{\alpha-1}
\end{gathered}
$$

in which the Lagrange multiplier denoted $m c_{j, t}^{n o m}$ can be interpreted as the (nominal) marginal cost associated with an additional unit of capital or labor. Rearranging further gives an optimal capital to labor ratio which is the same for all intermediate firms in equilibrium.

\footnotetext{
${ }^{16}$ It can be that firms adjust their price more frequently when disaster risk goes up. In Isoré and Szczerbowicz (2013), we considered both time- and state-dependent price-adjustment settings. In the latter case, the probability of not adjusting one firm's price can be thought of as a decreasing function of disaster risk. Yet, the results are not significantly different, such that we chose not to include this additional channel of disaster risk here.
} 
Let's now consider the inter-temporal problem of a firm that gets to update its price in period $t$ and wants to maximize the present-discounted value of future profits. Given the (real) profit flows that read as $\frac{p_{j, t}}{p_{t}} Y_{j, t}-m c_{t}^{*} Y_{j, t}$ and the demand function $Y_{j, t}=\left(\frac{p_{j, t}}{p_{t}}\right)^{-\nu} Y_{t}$, the maximization problem is

$$
\max _{p_{j, t}} E_{t} \sum_{s=0}^{\infty}(\zeta)^{s} Q_{t+s}\left(\left(\frac{p_{j, t}}{p_{t+s}}\right)^{1-\nu} Y_{t+s}-m c_{t+s}^{*}\left(\frac{p_{j, t}}{p_{t+s}}\right)^{-\nu} Y_{t+s}\right)
$$

where discounting includes both households' stochastic discount factor, $Q_{t, t+s}$, and the probability $\zeta^{s}$ that a price chosen at time $t$ is still in effect at time $s$. After some simplification, the first-order condition is

$$
p_{j, t}^{*}=\frac{\nu}{\nu-1} E_{t} \frac{\sum_{s=0}^{\infty}(\zeta)^{s} Q_{t+s} p_{t+s}^{\nu} Y_{t+s} m c_{t+s}^{*}}{\sum_{s=0}^{\infty}(\zeta)^{s} Q_{t+s} p_{t+s}^{\nu-1} Y_{t+s}}
$$

which depends on aggregate variables only, so that $p_{t}^{*}=p_{j, t}^{*}$. Increases in this optimal price from one period to another will give us the reset inflation rate while increases in the current price level $p_{t}$ defines the current inflation rate. (see Appendix for more details.)

\subsection{Public authority}

Bonds clears with public debt issued by a public authority which raises taxes from the households. The public authority also sets up the nominal interest rate on bonds following a Taylor type rule as

$$
r_{t}=\rho_{r} r_{t-1}+\left(1-\rho_{r}\right)\left[\Phi_{\pi}\left(\pi_{t}-\bar{\pi}\right)+\Phi_{Y}\left(y_{t}-y^{*}\right)+r^{*}\right]
$$

\subsection{Equilibrium}

The optimality conditions for the three representative agents' problem described above are derived in Appendix. They are solved together with the aggregate constraints also described in Appendix.

\section{Calibration and steady-state analysis}

Table 1 summarizes our baseline calibration values. As for disaster risk values, we follow the empirical literature based on historical data. Evidence on disasters' size and frequency is quite mixed and highly dependent on the definitions and methods used for the estimation. In 
particular, Barro and Ursúa (2008)'s mean disaster size of $22 \%$ associated with a quarterly probability $0.9 \%$ ranges in between other studies. ${ }^{17}$ Yet, our qualitatively results are robust to alternative values of the mean and probability of disasters. The degree of persistence in the $\log$ probability of disaster, $\rho_{\theta}$, is set at 0.9 following Gourio (2009). In Section 4.2, different degrees of persistence are considered. Normalizing the standard deviation of $\log (\theta)$ to 1 , this implies a standard deviation of innovations of $\left(1-\rho_{\theta}^{2}\right)^{1 / 2} \approx 0.436$.

Table 1 - Baseline calibration values (quarterly)

\begin{tabular}{|c|c|c|}
\hline \multicolumn{3}{|c|}{ Disaster risk } \\
\hline $\bar{\theta}$ & mean probability of disaster & 0.009 \\
\hline$\Delta$ & size of disaster & 0.22 \\
\hline$\rho_{\theta}$ & persistence of (log) disaster risk & 0.9 \\
\hline$\sigma_{\theta}$ & std. dev. of innovations to (log) disaster risk & 0.436 \\
\hline \multicolumn{3}{|c|}{ Utility function } \\
\hline$\beta_{0}$ & discount factor & 0.99 \\
\hline $1 / \tilde{\psi}$ & elasticity of intertemporal subtitution & 0.5 \\
\hline$\gamma$ & risk aversion coefficient & 3.8 \\
\hline$\varpi$ & leisure preference & 2.33 \\
\hline \multicolumn{3}{|c|}{ Investment } \\
\hline$\delta_{0}$ & capital depreciation rate & 0.02 \\
\hline$\tau$ & capital adjustment cost & 0.3 \\
\hline $\bar{u}$ & utilization rate of capital & 1 \\
\hline \multicolumn{3}{|c|}{ Production } \\
\hline$\alpha$ & capital share of production & 0.33 \\
\hline$\zeta_{0}$ & Calvo probability & 0.8 \\
\hline$\nu$ & elasticity of substitution among goods & 6 \\
\hline$\mu$ & trend growth of productivity & 0.005 \\
\hline \multicolumn{3}{|c|}{ Public authority } \\
\hline$\psi_{\pi}$ & Taylor rule inflation weight & 1.5 \\
\hline$\psi_{Y}$ & Taylor rule output weight & 0.5 \\
\hline $\bar{\pi}$ & target inflation rate & 0.005 \\
\hline$\rho_{r}$ & interest rate smoothing parameter & 0.85 \\
\hline
\end{tabular}

Our utility function follows Gourio (2012)'s specification, such that we adopt the same parameters for the valuation of leisure $(\varpi=2.33)$ and the risk aversion coefficient $(\gamma=3.8)$. Alternative values of risk aversion are considered in Section 4.2. However, the EIS value for the baseline scenario is set at 0.5 , in line with the New Keynesian literature, and compared to the value of 2 chosen by Gourio (2012).

Most of the other values are conventional, in particular for the production function and the

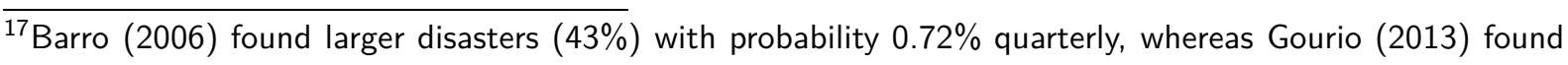
smaller disasters $(15 \%)$ with probability $0.5 \%$ quarterly. 
Taylor-type rule. The capital adjustment cost parameter is calculated so as to match the elasticity of the ratio $I / K$ with respect to the Tobin's q, in a standard way. This implies here a low value of $\tau=0.3$, and relates to the discussion of potential nonconvexity of the capital adjustment cost function in the presence of uncertainty (see Bloom (2009)). The standard Calvo probability of firms not changing their price $(\zeta=0.8)$ is compared to a flexible-price case where $\zeta=0$, for both values of the EIS.

Table 2 shows the steady-state values obtained under our calibration for some selected variables. In particular, we compare the economy without disaster, i.e having either a probability of disaster $(\bar{\theta})$ or a size of disaster $(\Delta)$ equal to zero, to the economy with disaster (for two example sizes, $\Delta=0.22$ and $\Delta=0.40)$. This is reported here for three different cases: flexible prices $(\zeta=0)$ and EIS $=2$ (economy à la Gourio), flexible prices and EIS $=0.5$, sticky prices $(\zeta=0.8)$ and EIS $=0.5$ (baseline scenario).

The role of the EIS is particularly worth discussing here. In the economy with an EIS below 1, agents have a high propensity to consume the certainty-equivalent income (see Weil (1990)). Thus, steady-state consumption has to be lower in the economy with disaster risk than the economy without. Intuitively, one can think that agents make precautionary savings if they expect a potential disaster to arrive. The same reasoning holds for providing more labor and capital initially in an economy that will be potentially affected by a disaster. Thus current output is higher. One can also see this higher 'degree of patience' in the (time-varying) discount factor and the stochastic discount factor. This holds whether prices are flexible or sticky.

On the contrary, with an EIS larger than 1, agents do not make so much precautionary savings and precautionary labor supply. Thus investment and output are lower, and by wealth effect so is consumption, when disaster risk is present in the economy versus not. Note that in both cases, the return on capital is of course decreasing in disaster risk. As one can also expect, the risk premium is nil in all cases as the agents make financial arbitrage with perfect foresight at the steady-state. The Tobin's q remains unchanged since the disaster risk does not affect directly the macroeconomic quantities of the detrended system, unlike a capital depreciation shock for instance.

Only in case when the EIS tends to unity, steady-state values tend to be equal in economies with and without disaster risk. Indeed, when the EIS is equal to 1 , the time-varying discount factor $(\beta(\theta))$ boils down to the usual discount factor $\beta_{0}$ (in equation (6)), and the disaster risk does not affect the economic outcomes anymore. This results is referred to as Tallarini (2000)'s "observational equivalence", stating that the macroeconomic quantities are unaffected by the amount of risk in the economy. Again, here as in Gourio (2012), this holds if and only if the 
Table 2 - Steady-state values for selected variables.

\begin{tabular}{rrr} 
no disaster risk & baseline disaster risk & larger disaster risk \\
$\Delta=0.22$ and $\bar{\theta} \rightarrow 0$ & $\Delta=0.22$ & $\Delta=0.4$ \\
or $\Delta=0$ and $\bar{\theta}=0.9 \%$ & $\bar{\theta}=0.9 \%$ & $\bar{\theta}=0.9 \%$ \\
\hline
\end{tabular}

EIS $=\mathbf{0 . 5}$, sticky prices $(\zeta=0.8)$

output (detrended)

0.614

0.625

0.651

consumption (detrended)

0.499

0.505

0.518

investment (detrended)

0.115

0.121

0.133

labor

0.228

0.229

0.232

capital (detrended)

4.608

4.820

5.332

$\beta(\bar{\theta})$

0.990

0.991

0.993

Tobin's q

1

1

1

wage

1.505

1.525

1.570

capital rental rate

0.037

0.036

0.034

stochastic discount factor

0.984

0.986

0.990

return on capital

1.017

1.014

1.010

(gross) risk premium

1

1

1

EIS $=\mathbf{0 . 5}$, flexible prices $(\zeta=0)$

\section{output (detrended)}

consumption (detrended)

investment (detrended)

labor

capital (detrended)

$\beta(\bar{\theta})$

Tobin's q

wage

capital rental rate

stochastic discount factor

return on capital

(gross) risk premium

\begin{tabular}{rrr}
0.614 & 0.626 & 0.652 \\
0.499 & 0.505 & 0.518 \\
0.115 & 0.120 & 0.133 \\
0.228 & 0.229 & 0.232 \\
4.604 & 4.818 & 5.333 \\
0.990 & 0.991 & 0.993 \\
1 & 1 & 1 \\
1.506 & 1.526 & 1.572 \\
0.037 & 0.036 & 0.034 \\
0.984 & 0.986 & 0.990 \\
1.017 & 1.014 & 1.010 \\
1 & 1 & 1 \\
\hline
\end{tabular}

EIS $=2$, flexible prices $(\zeta=0)$

output (detrended)

consumption (detrended)

investment (detrended)

labor

capital (detrended)

$\beta(\bar{\theta})$

Tobin's q

wage

capital rental rate

stochastic discount factor

return on capital

(gross) risk premium

$\begin{array}{rrr}0.642 & 0.635 & 0.623 \\ 0.513 & 0.510 & 0.504 \\ 0.128 & 0.125 & 0.119 \\ 0.230 & 0.230 & 0.229 \\ 5.129 & 5.008 & 4.766 \\ 0.990 & 0.990 & 0.989 \\ 1 & 1 & 1 \\ 1.554 & 1.543 & 1.521 \\ 0.034 & 0.035 & 0.036 \\ 0.986 & 0.987 & 0.988 \\ 1.014 & 1.013 & 1.012 \\ 1 & 1 & 1\end{array}$


EIS is equal to one. In all other cases, quantities differ from the economy without disaster risk.

\section{Impulse Response Functions}

In this Section, we simulate the effect of a rise in the small probability of disaster $(\theta)$ from the stochastic steady-state. Unless specified, the approximation is made at the third-order such that asset pricing and macroeconomic variables interact with each other. ${ }^{18}$ Our aim here is essentially qualitative, and consists in comparing the effect of the shock in the following four cases:

(i) With flexible prices and EIS $=2$, a decentralized version of Gourio (2012)'s economy, in order to nest his results as a particular case;

(ii) Still under flexibles prices but with $E I S=0.5$, i.e a value more in line with the standard RBC and New Keynesian literatures and with micro estimates. Gourio (2012)'s results are then found to be reversed;

(iii) With sticky prices and the same EIS $=0.5$, as for our baseline scenario. The recessionary effect is then restored and generalized;

(iv) With sticky prices and EIS $=2$, the mirroring case of $(i i i)$.

Since we use perturbation methods here, we consider a very small deviation from the itself very small probability of disaster at the steady-state, more specifically a change from $\bar{\theta}=0.009$ to 0.01 . As a consequence, the size of the responses that we get will naturally be small as well. A larger shock could of course give a better feel for the magnitude of the effects we are describing here, yet this would be at the price of potentially large errors. ${ }^{19}$ In addition, we try some alternative calibration values, and finally simulate the responses of the model to a standard monetary policy shock. This allows to check the accuracy of our model in replicating well-known perturbation responses in spite of the presence of disaster risk.

\subsection{Effects of a disaster risk shock: qualitative effects}

\subsubsection{Case 1: flexible prices and EIS $=2$ (à la Gourio, 2012)}

Figure 1 shows the effect of the disaster risk shock in an economy à la Gourio (2012), here in a decentralized market version instead of the RBC model, with flexible prices $(\zeta=0)$ and an EIS of 2, according to his calibration. The shock makes the agents more impatient $(\beta(\theta)$

\footnotetext{
${ }^{18}$ Indeed, the risk premium is nil in the first-order, constant at the second-order, but fluctuates in response to the disaster risk shock with a third-order approximation.

${ }^{19}$ Using projection methods, Gourio (2012) considers a deviation from $0.72 \%$ to $4 \%$ for the probability of disaster. His results indicate the magnitude of the effects of a disaster risk shock, while we mostly focus on the sign of the responses here.
} 
Figure 1 - Impulse responses to a rise in $\theta$ from $0.9 \%$ to $1 \%$, in Case $1: \zeta=0$ and EIS $=2$. Vertical axis: percentage change from the stochastic steady-state. Third-order approximation.
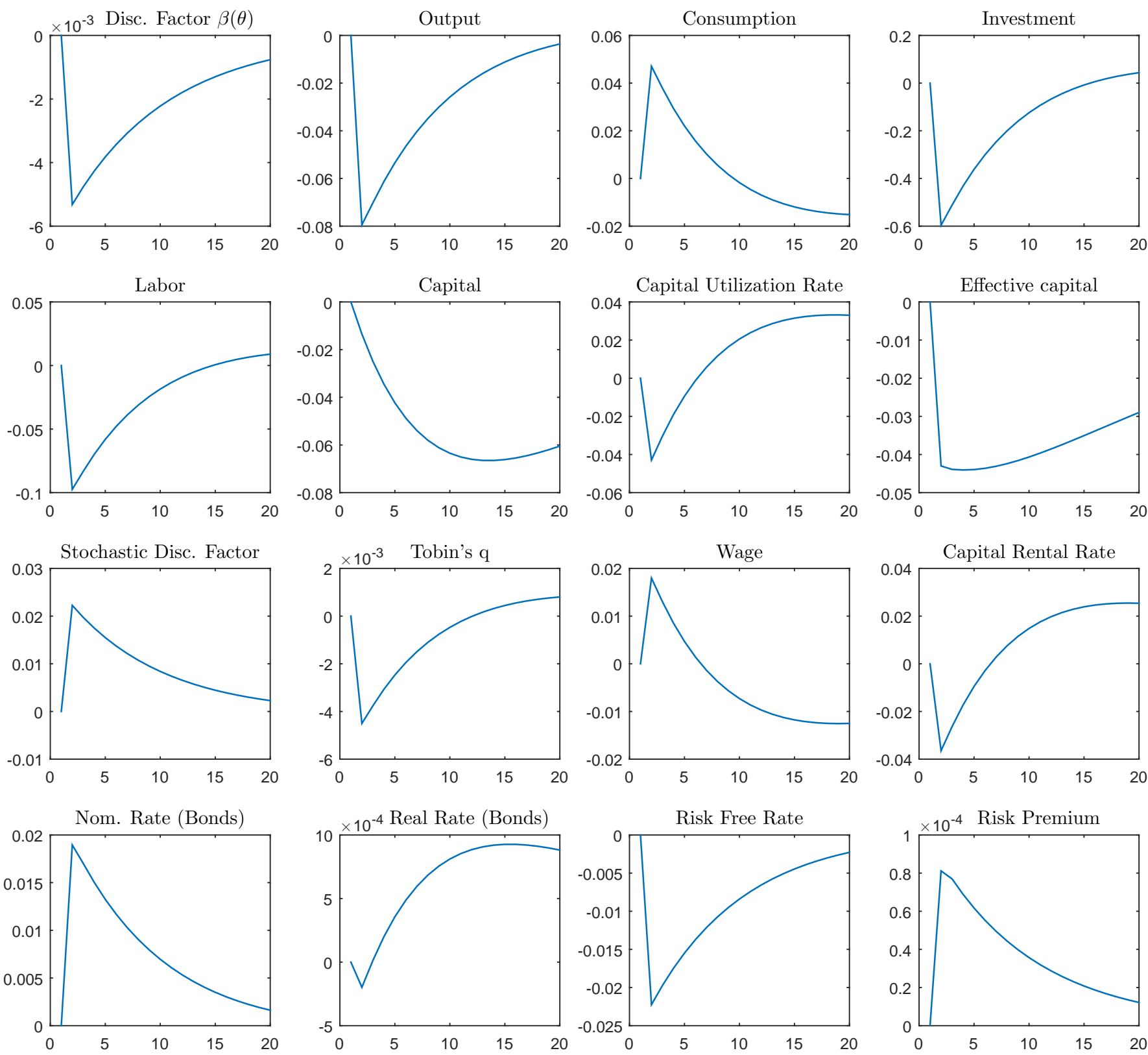
decreases). Hence, they save and thus invest less, such that the economy enters a recession, while the risk premium goes up. However, agents then consume more and work less, so the wage increases. These results are identical to Gourio (2012)'s and partly consistent with the evidence on disaster risk (see Barro (2006) or Gourio (2008) for instance). However, these predictions rely on accepting an EIS greater than 2, which contrasts with commonly accepted values. We propose to look for the responses with a different EIS in Case 2 below.

\subsubsection{Case 2: flexible prices and $E I S=0.5$}

In this case, we just changed the value of the EIS to 0.5 compared to the previous case. As one can see on Figure 2, this is enough to make the sign of most variables completely opposite. Contrary to Case 1, a low EIS implies that agents' propensity to save increases with the disaster risk. This is captured here by an increase in the discount factor, that can be interpreted as a higher degree of patience. This makes the agents save more and invest more. The lower consumption on impact does not have much effect on the total output response. The price of goods drops on impact but rises immediately after (since there is no price rigidity in this case). Hence firms expect the deflation to be short and want to increase their demand for production factors, as well as the utilization rate of capital. Therefore, the rental rate of capital goes up, making the households willing to invest more. Overall, the rise in investment is higher than the drop in consumption, such that the economy enters a boom. As consumption decreases, the marginal utility increases, so the labor supply increases and the wage goes down despite the boom.

As far as asset pricing is concerned, we can see here that the risk premium still goes up because the disaster risk shock makes it more risky to invest in the capital stock. But, in this case, it implies that the risk premium becomes procyclical, which is highly counterfactual. Also note that, by making the EIS smaller, the magnitude of the increase is now larger than in Case 1.

\subsubsection{Case 3: sticky prices and EIS $=0.5$ (baseline scenario)}

Figure 3 depicts the responses to the same shock in the sticky-price economy with an EIS below unity. Similarly to Case 2 , a low EIS makes the agents more patient $(\beta(\theta)$ increases) following the disaster risk shock, which gives them an incentive to save and thus consumption decreases. However, price stickiness also makes investment decrease on impact, such that the output now drops as well. This is because prices do not fall enough to clear the markets such that firms demand less factors of production. We indeed observe a fall in the utilization rate of capital, hence in the effective capital, and in turn the rental rate of capital making the households less willing to invest. ${ }^{20}$ For the same reason, labor now also drops, as well as

\footnotetext{
${ }^{20}$ The same effect is present in Basu and Bundick (2014) who found opposite responses of investment to uncertainty shocks under sticky versus flexible prices.
} 
Figure 2 - Impulse responses to a rise in $\theta$ from $0.9 \%$ to $1 \%$, in Case $1: \zeta=0$ and EIS $=0.5$. Vertical axis: percentage change from the stochastic steady-state. Third-order approximation.
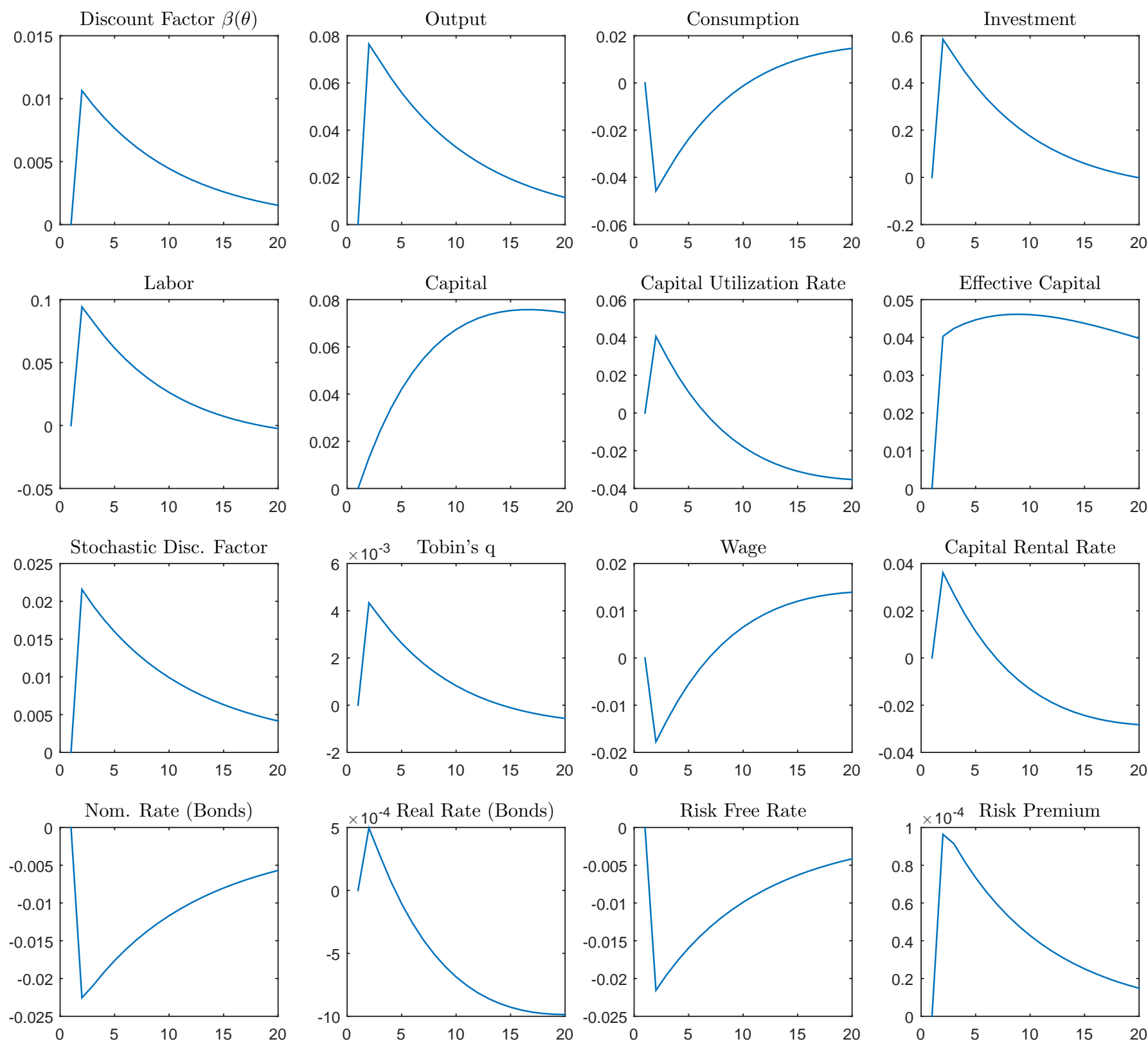
Figure 3 - Impulse responses to a rise in $\theta$ from $0.9 \%$ to $1 \%$, in Case $3: \zeta=0.8$ and EIS $=0.5$. Vertical axis: percentage change from the stochastic steady-state. Third-order approximation.
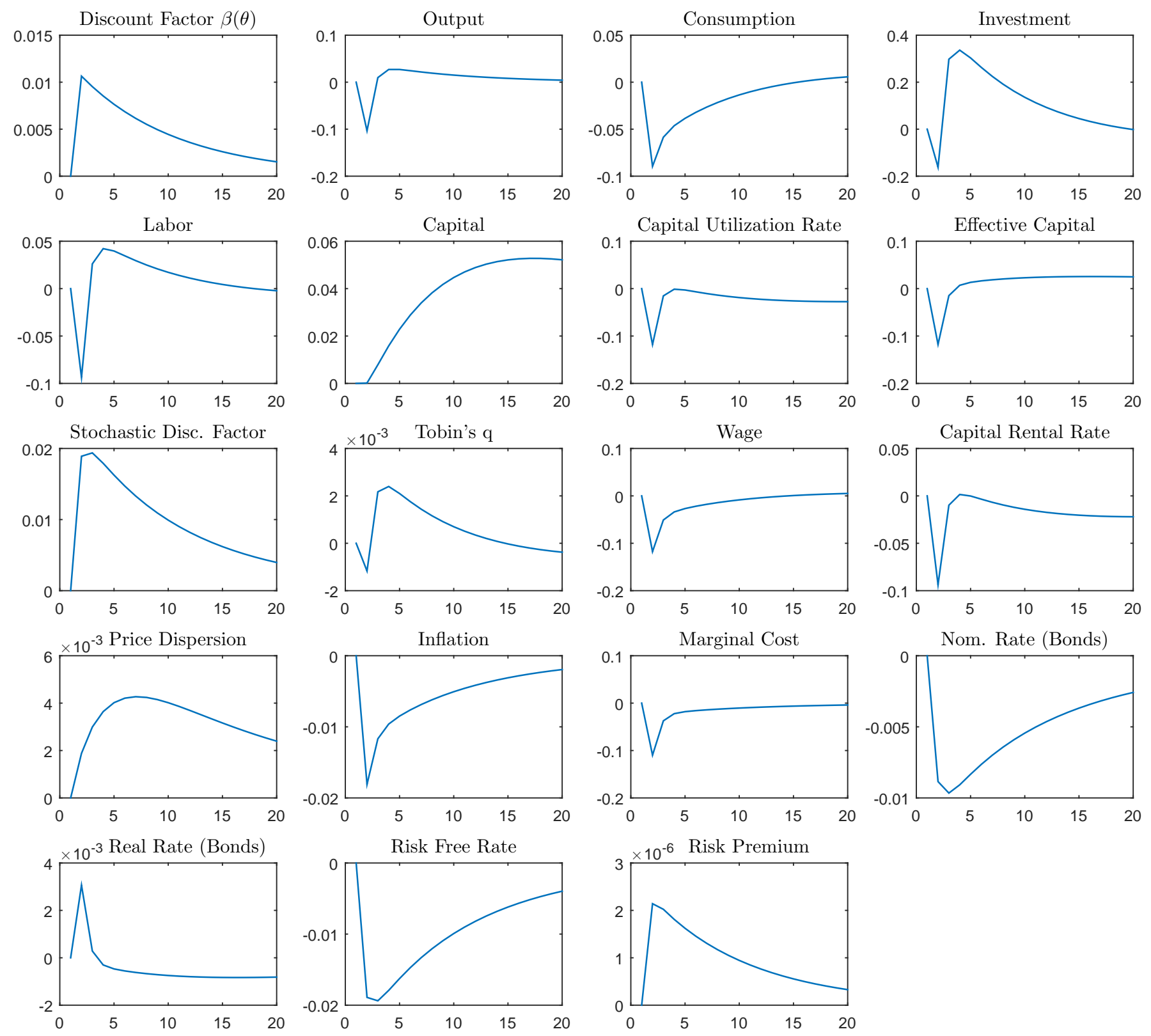
wages which was not the case in the economy à la Gourio (Case 1). ${ }^{21}$ In short, sticky prices allow to generate positive co-movements between the main macroeconomic aggregates, i.e consumption, investment, output, labor, wages, and inflation, as observed in the data.

As for asset prices, we observe a 'flight-to-quality' effect that is visible through the drop in the riskfree rate when the disaster risk shock hits. This drop in the riskfree rate is of similar magnitude as in Case 1, suggesting that sticky prices may provide a solution to avoid an excessive change in the riskfree rate despite having an EIS smaller than one, as discussed before. Finally, the risk premium also increases here due the disaster risk shock. When compared to the economy à la Gourio (Case 1), the magnitude of this increase is lower here. However, moving from an EIS larger than one to an EIS smaller than one always increases the response of the risk premium to the disaster risk shock, for a given degree of price stickiness/flexibility (comparing Cases 1 and 2 on one hand, and Cases 3 and 4 on the other).

The overshooting in labor, investment, and output in a lower extent, after the initial impact of the shock is also worth describing. Both labor and investment responses are affected by two opposite channels. One is the lower demand for factors from firms discussed above. The other is a precautionary motive from the households when the disaster risk goes up. Indeed, the agents want to limit the decrease in their consumption by acquiring more capital and increasing their labor supply when a disaster becomes more likely (under the assumption of an EIS below one). This upward pressure turns to outweight the first effect in the subsequent periods after the shocks. Recall that the households cannot buy the riskfree asset in our economy, such that investment and risky bonds are the only available vehicles for savings, making the size of this overshooting quite large. ${ }^{22}$ The observed overshooting in output is the consequence of the pattern for labor and investment. It is actually a relatively common feature in models with uncertainty shock. In particular, Bloom (2009) shows that considering nonconvex capital adjustment costs can however make investment decrease more persistently.

Overall, disaster risk effects on macroeconomic quantities here happen to coincide with discount factor shocks, whether in level or in volatility, in the literature. They are indeed reminiscent of exogenous 'preference shocks' à la Smets and Wouters (2003) and Christiano et al. (2011) on the one hand, and 'uncertainty shocks' (defined as second-moment shocks to the discount factor) as in Leduc and Liu (2012) or Basu and Bundick (2014). In exhibiting a short sharp recession followed by an "overshooting" in the recovery, our reponses also echo very

\footnotetext{
${ }^{21}$ Similarly, Leduc and Liu (2012) find that nominal rigidities amplify the effect of uncertainty shocks on the unemployment rate through declines in aggregate demand.

${ }^{22}$ This assumption of the model could be released but then the detrending method à la Gourio (2012) could not be perfectly applied. In that case, we would have to make an assumption about the current state of the economy as being in a 'disaster' regime or not when generating the impule response functions. It would be straightforward to do so, and the approach that we choose here is just a question of preference for unconditional impulse response functions, closer to the spirit of Gourio (2012).
} 
much Bloom (2009)'s effects of uncertainty. In that respect, the disaster risk can provide a potential explanation for exogenous shifts in preferences or changes in aggregate uncertainty. In addition, the countercyclicality of the risk premium following the disaster risk shock à la Gourio (2012) is meanwhile preserved.

\subsubsection{Case 4: sticky prices and EIS $=2$}

In this last scenario, we change again the EIS for a value larger than unity, but still under sticky prices. As we can observe in Figure 4, the same increase in $\theta$ now makes the timevarying discount factor drop again. All the other responses are thus the exact opposite to those in Figure 3. In particular, there is a boom (as in Case 2) in output, driven by increases in consumption and investment (unlike Case 2). This Case is not a realistic scenario for a disaster risk shock, yet it provides an interesting counterfactual exercise to confirm $(i)$ the effect of the EIS on the discount factor and the propensity to consume/save, and (ii) the fact that the model with nominal rigidity is driven primarily by the response in consumption to the disaster risk shock while the flexible-price version is primarily driven by the supply-side of the economy for a given value of the EIS. Here again, sticky prices allow to reproduce positive co-movements of consumption and investment. We can also observe that the riskfree rate happens to decrease more than in Case 3 where the EIS was low. This implies that the disaster risk argument about a high value of the EIS being necessary to limit the fall of the riskfree rate does not hold anymore when prices are sticky.

Figures 5 and 6 summarize together the responses in the economy à la Gourio (2012) and in our baseline economy in the same graphs, for easier comparison, successfully at first- (Figure 5) and third-order (Figure 6) approximations.

\subsection{Sensitivity analysis}

Some alternative calibration values are considered when simulating the effect of our disaster risk shock in the baseline scenario (small EIS, sticky prices). The responses are given in Figure 7 for selected variables. It turns out that the qualitative results we emphasize in this paper are essentially unaffected.

The first value to be considered is the risk aversion coefficient. Our baseline value is standard under Esptein-Zin specification, i.e lying typically between 3 and 4. Barro and Jin (2011)'s estimates in the presence of disaster risk are particularly informative. Yet, we try alternative values of $\gamma$ within the range allowed by the model, i.e compatible with an (endogenous) discount factor $\beta(\theta)$ below unity. When the agents are closer to risk neutrality $(\gamma=1.5)$, the upward precautionary labor supply effect causing the overshooting in labor, investment, 
Figure 4 - Impulse responses to a rise in $\theta$ from $0.9 \%$ to $1 \%$, in Case $3: \zeta=0.8$ and EIS $=2$. Vertical axis: percentage change from the stochastic steady-state. Third-order approximation.
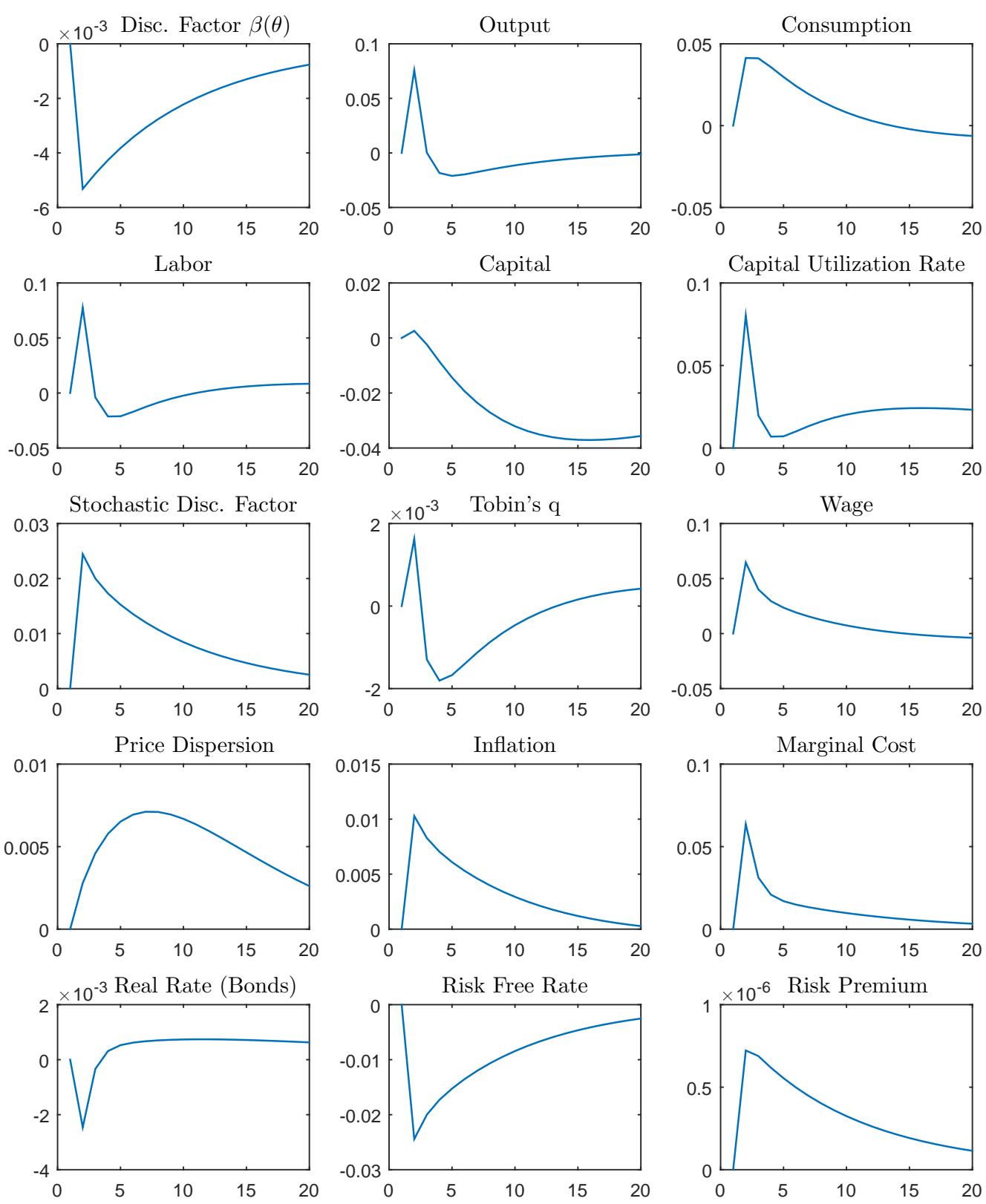
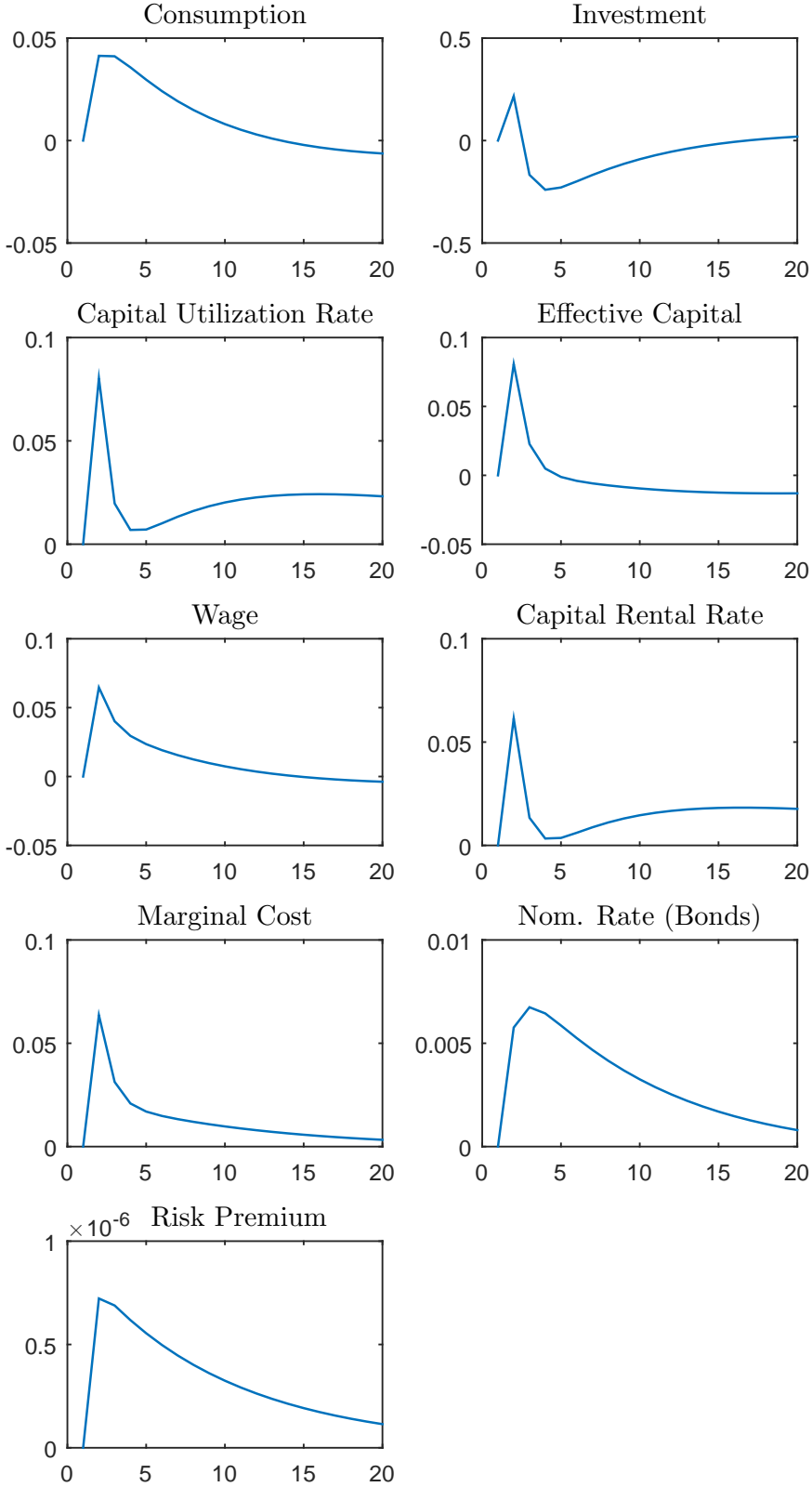
Figure 5 - Impulse responses to a rise in $\theta$ from $0.9 \%$ to $1 \%$, comparing Case 1 (à la Gourio) and Case 3 (baseline), with a first-order approximation. Vertical axis: percentage change from the stochastic steady-state.
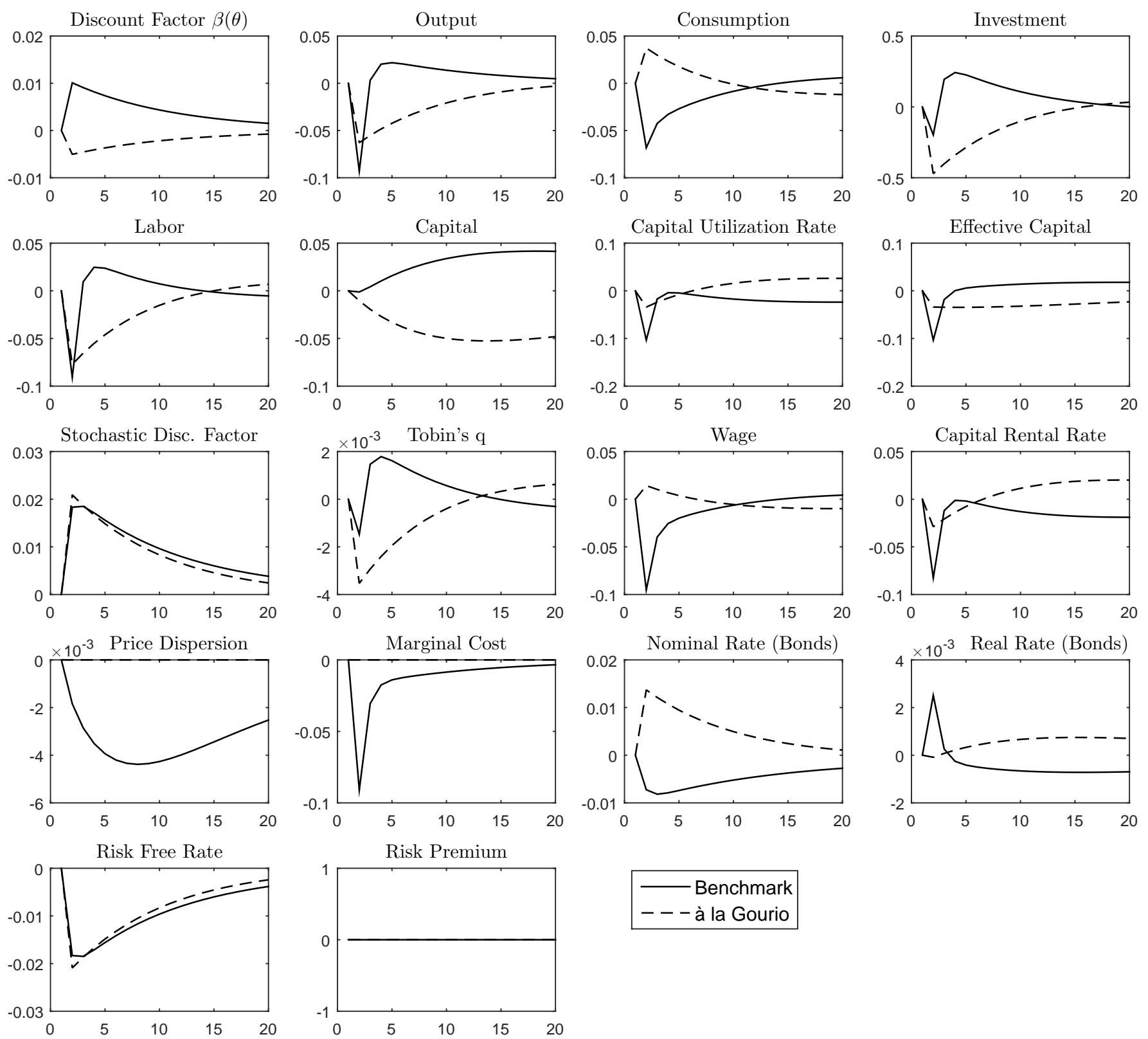
Figure 6 - Impulse responses to a rise in $\theta$ from $0.9 \%$ to $1 \%$, comparing Case 1 (à la Gourio) and Case 3 (baseline), with a third-order approximation. Vertical axis: percentage change from the stochastic steady-state.
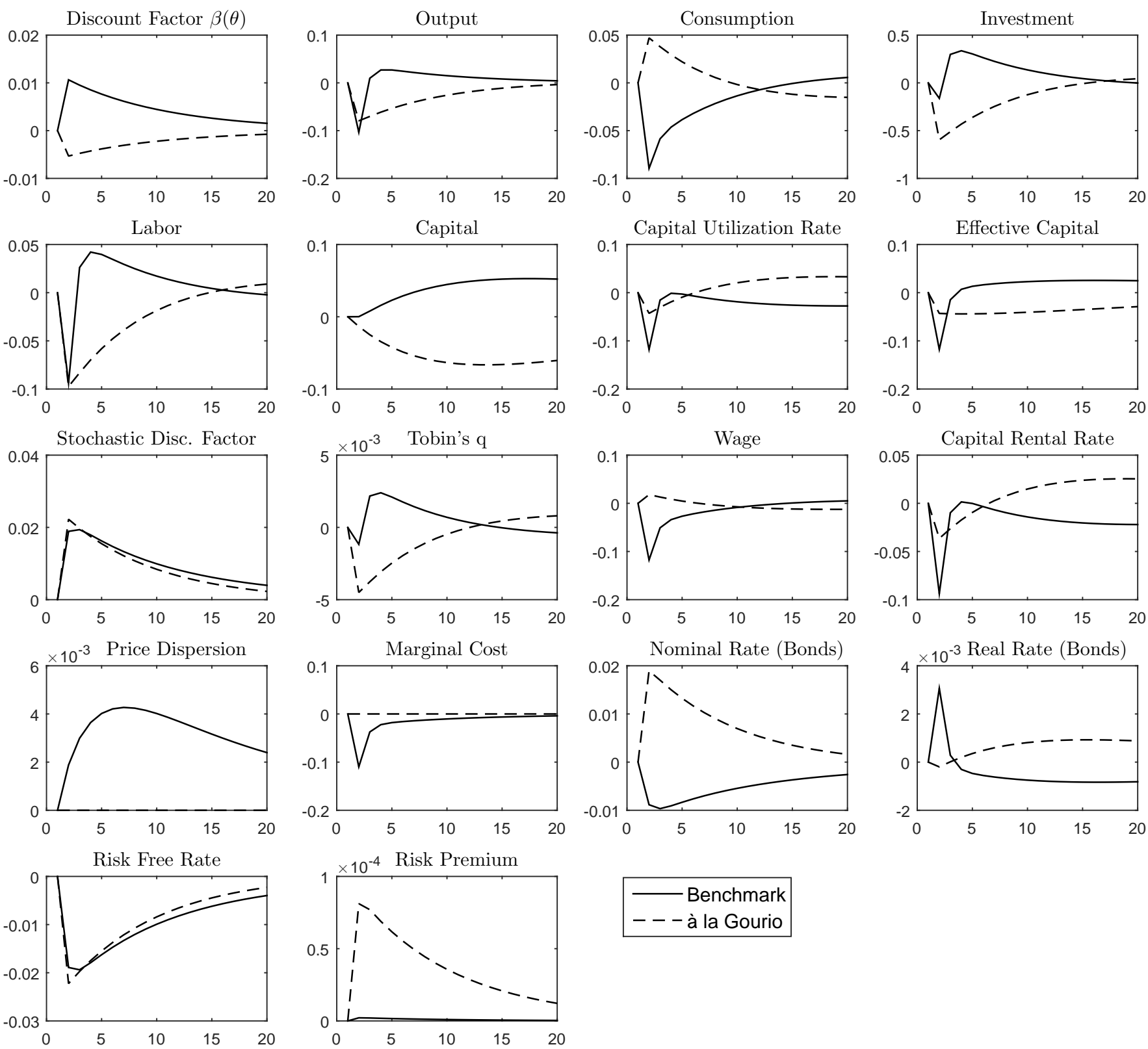
Figure 7 - Responses (in percentage change) to a rise in $\theta$ from $0.9 \%$ to $1 \%$ (baseline calibration, third-order), for alternative levels of parameters.

- Risk aversion coefficient, $\gamma$
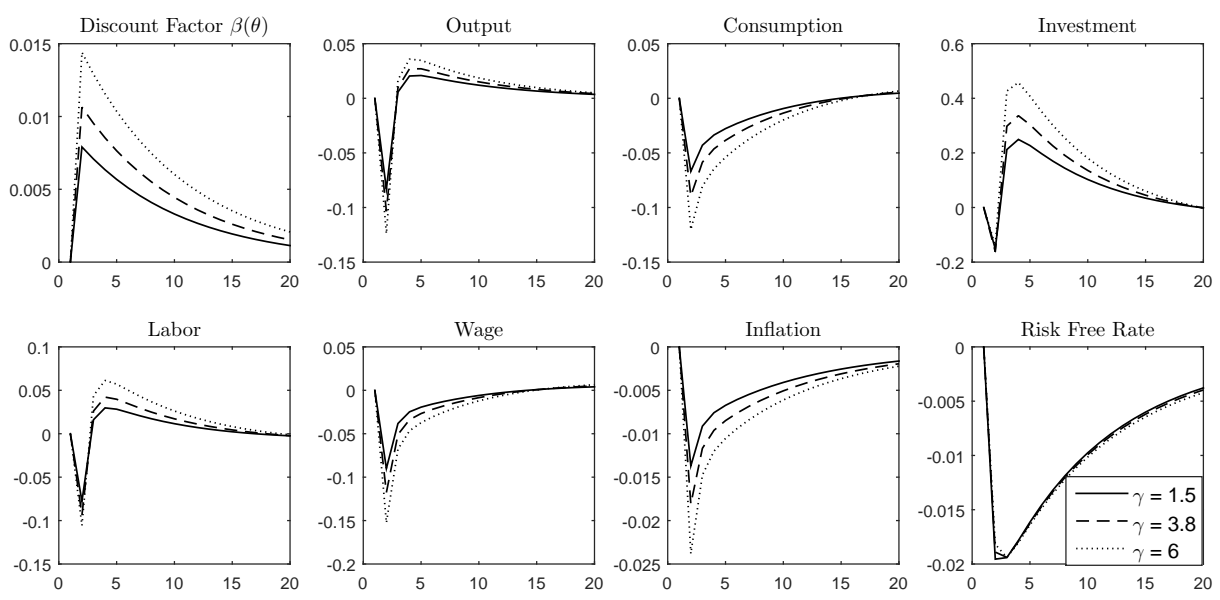

- Discount factor in the absence of disaster risk, $\beta_{0}$
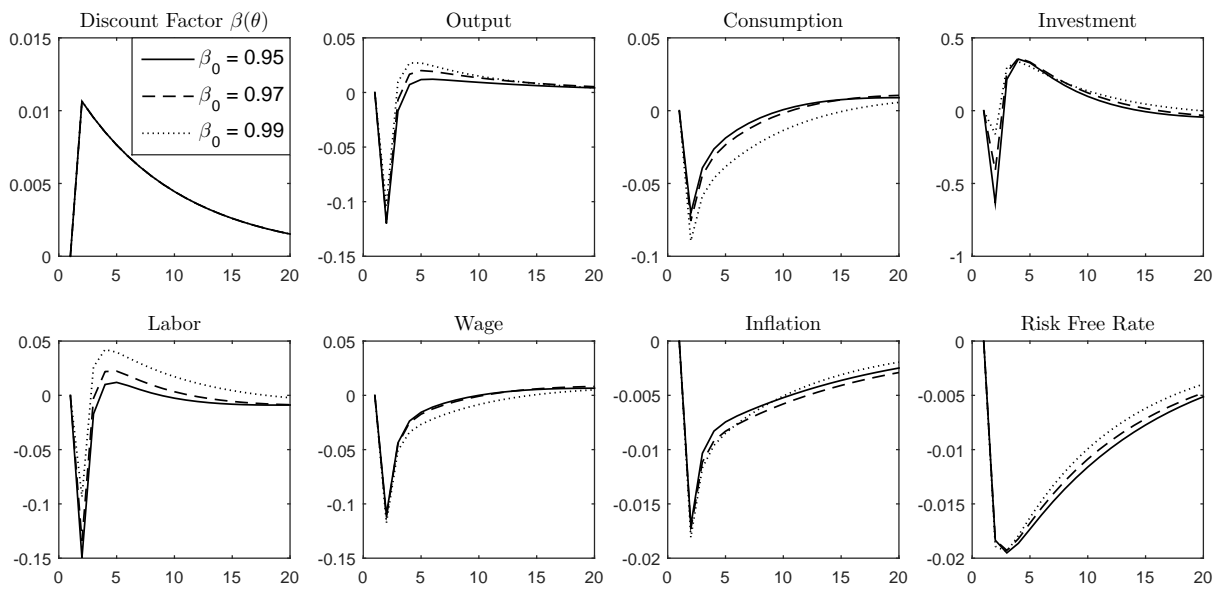

- Steady-state probability of disaster, $\bar{\theta}$
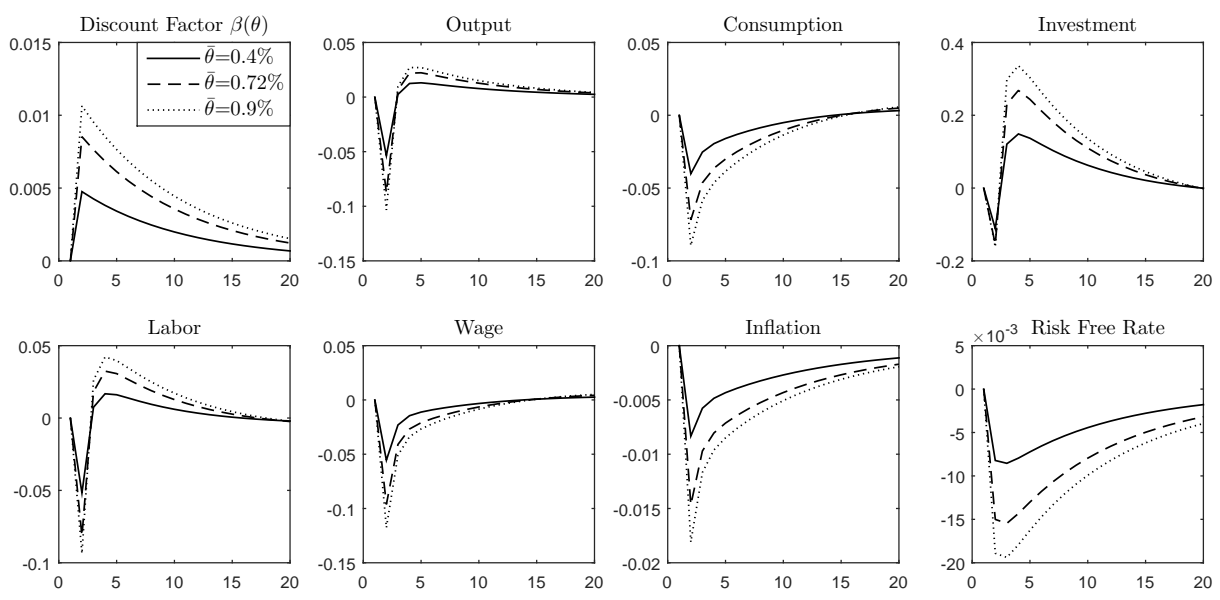
- Size of disaster, $\Delta$
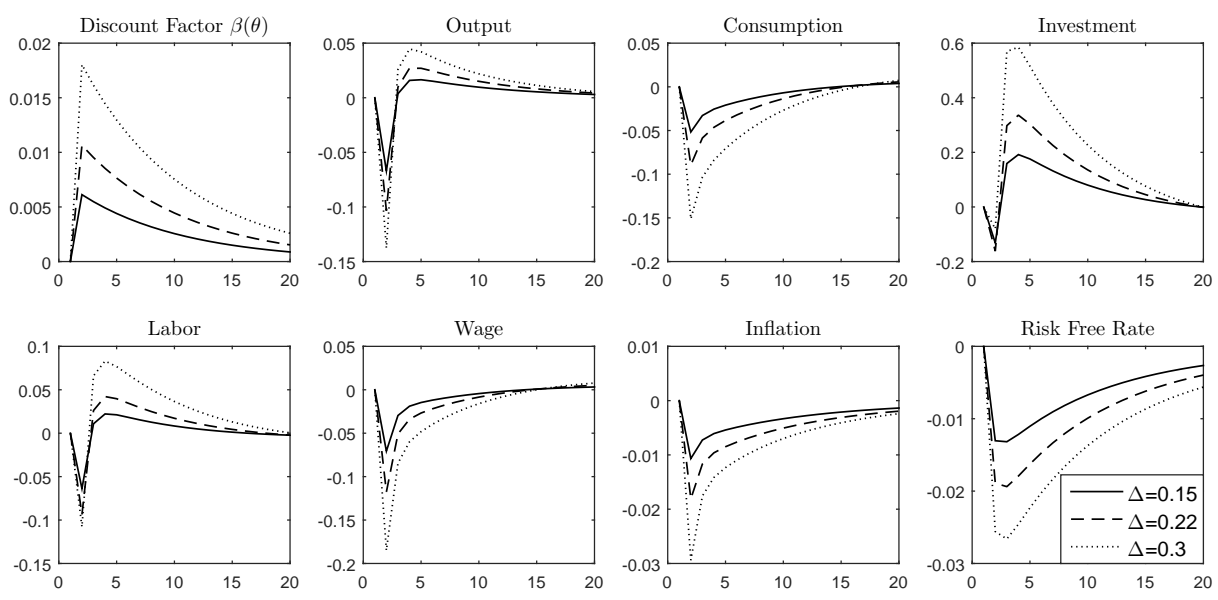

- Persistence of disaster probability, $\rho_{\theta}$
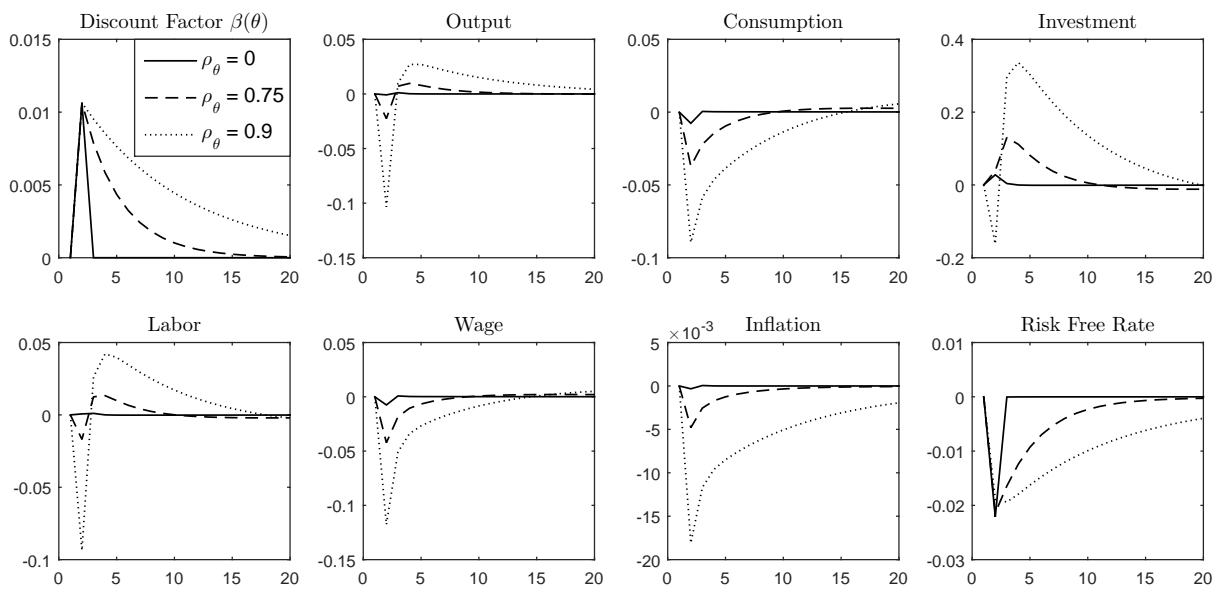

Figure 8 - Responses (in percentage change) to a $1 \%$ change in the nominal interest rate on bonds (baseline calibration)
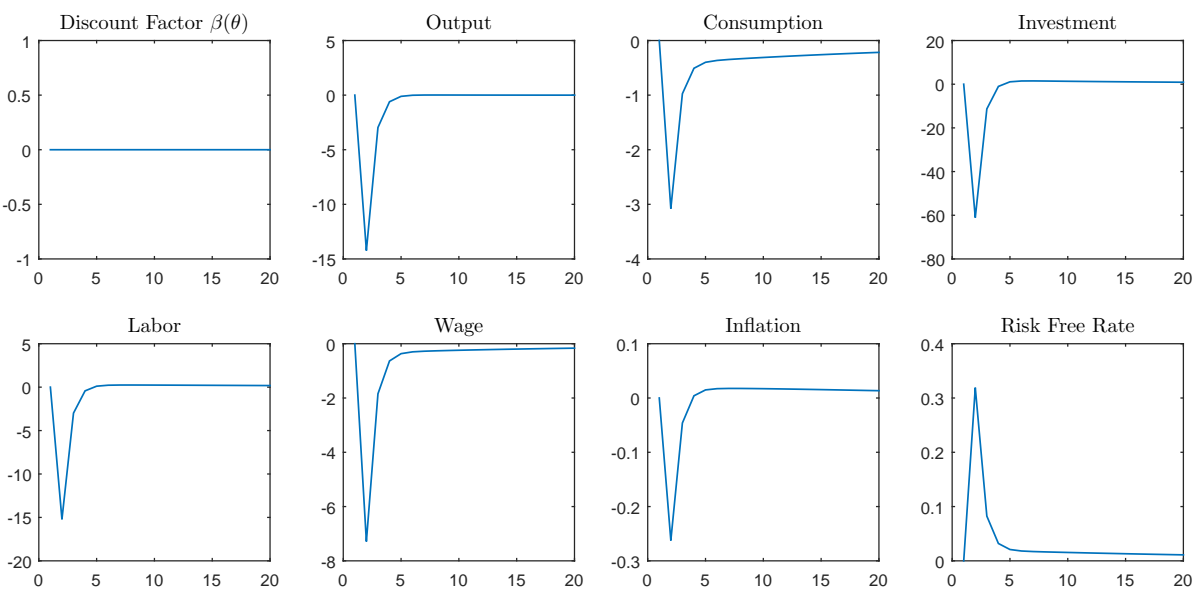

and output, turns to be more moderate. On the contrary, high risk aversion (here, $\gamma=6$ ) systematically amplifies the responses, yet without questioning the qualitative effects. 
Similarly, alternative values for the fundamental discount factor $\beta_{0}$ (that holds in the absence of disaster risk), the mean disaster size $\Delta$, or the mean probability of disaster $\bar{\theta}$, have size but not sign effects.

The persistence in disaster risk, $\rho$, has however a qualitative effect on the response of investment. As discussed above, investment is driven by two opposite effects and it happens that the upward pressure (the precautionary motive) tends to outweight the downward pressure (firms' lower demand for factors of production) when the persistence is low. Once again, should the households be allowed to buy the riskfree asset in our model setup, this effect may vanish as precautionary savings would find another vehicle than investment. Overall, this response of investment is also yet not sufficiently strong to modify the response of output to the disaster risk shock. Indeed, a recession still hits on impact. The size of the subsequent overshooting is however negatively correlated with the persistence in disaster risk.

Finally, Figure 8 displays the responses to a monetary policy shock for the baseline scenario. These responses are quite standard and inform us about the validity of the model to well-known shocks.

\section{Discussion}

\subsection{The literature on disaster risk}

The literature on rare events has emerged in the 1980s when macroeconomic models were struggling to explain the dynamics of asset prices and their related risk premia. Rietz (1988) has shown that introducing a low probability of an economic disaster into an endowment economy was able to address the the equity premium puzzle (Mehra and Prescott, 1985). ${ }^{23}$

Estimating economic disasters on US data over the twentieth century, Barro (2006) found a frequency of $1.7 \%$ per year and an average size of $29 \%$. Using these results to calibrate an extended version of Rietz (1988)'s model, Barro confirmed that rare disasters could capture high equity premium and low risk-free rate puzzles. Barro and Ursúa (2008) have further extended Barro (2006) by including data on consumption, more relevant for asset pricing models. They assembled international time series since 1870 and found disaster probabilities of around $3.6 \%$ per year with a mean disaster size of $22 \%$. They simulate a Lucas-tree model with i.i.d. growth shocks and Epstein-Zin-Weil preferences and obtain plausible equity premium

\footnotetext{
${ }^{23}$ Other solutions that have been proved able to improve asset pricing of macroeconomic models include notably consumption habits and heteroscedastic shocks (Campbell and Cochrane, 1999) and Epstein-ZinWeil preferences, separating the risk aversion coefficient from the EIS, combined with stochastic volatility in consumption growth (Bansal and Yaron, 2004). Epstein-Zin-Weil preferences alone contribute only partially to the solution of the equity premium puzzle: in Weil (1989) for instance the risk aversion coefficient must be set at 45 and EIS at 0.1 for a reasonable match with the data to be obtained.
} 
on levered equity, with a coefficient of relative risk aversion of $3.5 .^{24}$

Despite encouraging results, Rietz (1988), Barro (2006) and Barro and Ursúa (2008)'s models were not able to explain some asset pricing moments such as the volatility of price-dividend ratios for stocks, the volatility of bond risk premia, and return predictability. ${ }^{25}$ This is essentially due to the fact that they assume the probability of disaster to be constant. Thus, Gabaix (2008) made it time-varying and introduced it in an endowment economy, before Gabaix (2011, 2012) and Gourio $(2012,2013)$ further considered real business cycle frameworks. A time-varying probability of disaster is indeed able to explain volatility patterns of asset prices and return predictability (Wachter, 2013, Seo and Wachter, 2013). It also solves a number of macrofinance puzzles such as the risk-free rate puzzle or the upward-sloping nominal yield curve (Gabaix, 2012).

Gabaix's (2012) framework is constructed such that variations in the probability of disaster have no impact on macroeconomic quantities. This is reminiscent of Tallarini (2000)'s theorem that macroeconomic dynamics, unlike asset prices, are basically unaffected by changes in aggregate risk. In contrast, Gourio (2012) found that Tallarini (2000)'s "observational equivalence" holds for the presence of disaster risk if and only if the EIS is exactly equal to unity. However, he shows that, as soon as the EIS differs from unity, a shock to the probability of disaster is equivalent, under some assumptions, to a preference shock. His model thus predicts a correlation between asset prices and macroeconomic quantities which is supported empirically.

We here build on Gourio (2012)'s modeling of the disaster risk and incorporate it into a fullfleshed New Keynesian model, featuring monopolistic competition, capital adjustment costs, sticky prices, and a Taylor-type rule. To the best of our knowledge, we are the first paper to do so. Thereby, we show that Gourio (2012)'s results can be conciliated with a value of the EIS smaller than unity, and thus generalize them in a framework more suitable for future policy analysis.

\subsection{Evidence and calibration of the EIS}

There is no clear consensus about the value of EIS in the literature. It is standard in macroeconomic calibrations to take a value smaller than one, whether the utility function is Epstein-Zin and thus the EIS chosen independently from the risk aversion coefficient (Rudebusch and Swanson (2012), Caldara et al. (2012), use both a value of 0.5) or with standard timeadditive preferences (Piazzesi et al. (2007) choose 0.2, Smets and Wouters (2007) 0.66). In contrast, macrofinance real business cycles often choose a value higher than unity to match

\footnotetext{
${ }^{24}$ Barro and Jin (2011) estimate the risk aversion coefficient from dataset on disasters. They found a mean close to 3, with a 95\% confidence interval for values from 2 to 4 .

${ }^{25}$ In Barro and Ursúa (2008), the price-dividend ratio and the risk-free rate are constant.
} 
asset pricing moments (Barro and Ursúa (2008), Gourio (2012), Nakamura et al. (2013) have chosen a value of 2).

This dispersion is due to the fact that empirical evidence on the value of the EIS is yet not conclusive. An influential paper by Hall (1988) found this parameter to be close to zero, and a subsequent literature has provided further support for values smaller than one (see e.g Campbell and Mankiw (1989), Ludvigson (1999), Yogo (2004)). ${ }^{26}$ However, at least two types of concerns about these estimates have been raised. First, agents' heterogeneity matters. Blundell et al. (1994) and Attanasio and Browning (1995) find that rich households tend to show a exhibit EIS. Mankiw and Zeldes (1991) and Vissing-Jorgensen (2002) find a larger EIS for stockholders than for non-stockholders. Bayoumi (1993) finds that liquidityconstrained households' EIS is smaller. Second, the presence of uncertainty is an important factor for the estimation of the EIS. Bansal and Yaron (2004) argued that ignoring timevarying consumption volatility leads to a downward bias in the macro estimates. Beeler and Campbell (2012) used an instrumental variable approach to circumvent that concern and find that, although the downward bias exists, it is not large enough to explain the low empirical estimates. It seems however, that their regression approach is highly sensitive to samples, assets used, and instruments, as pointed out by Bansal et al. (2012).

While discussion on the empirical measure of the EIS is still ongoing, this parameter has critical implications on the theory side. As mentionned earlier, the macroeconomic literature has reached the consensus of an EIS below unity for well-behaved responses to shocks. On the other hand, asset pricing models have often adopted a value larger than unity in order to replicate observed moments, in particular the equity premium, the volatility of financial returns, and their variations over time. In that vein, finance-oriented models of disaster risk have also set an EIS above unity in order to prevent the risk-free rate from declining too much, and thus asset prices to rise, by reducing the precautionary saving effect in response to a disaster risk shock (see the discussion in Tsai and Wachter, 2015).

In trying to disentangle the role of the EIS in replicating asset pricing moments, Yang (2015) compares a model with habit in consumption with a model of long-run risk. He finds that the former requires an EIS equal to unity whereas the latter requires an EIS strictly above unity in order to match the equity premium. However, in the presence of disaster risk, appropriate levels of equity premium and volatility of government bonds can be compatible with a low EIS, as recently estimated by Irarrazabal and Parra-Alvarez (2015) on Wachter (2013)'s model. Yet,

\footnotetext{
${ }^{26}$ Havránek et al. (2015) have collected 2,735 estimates of EIS reported in 169 studies to explore estimation differences across countries and methodologies from a meta analysis. They find a mean estimate around 0.5 , and typically lying between 0 and 1 . They suggest that the type of utility function does not affect much, while cross-country differences matter, yet essentially preserving an EIS below unity. Households' EIS appears to be larger in countries with higher income per capita and higher stock market participation.
} 
a high EIS is still necessary to generate higher price-dividend volatility, stock market volatility, and hence a lower Sharpe Ratio, in that model.

Our paper thus contributes to that debate in showing that both macroeconomic and financial effects of disaster risk can be obtained when the EIS is below unity and prices are sticky. Specifically, on the macro side, positive co-movements between the main aggregates - output, consumption, investment, labor, wages, and inflation - as observed in the data, and, on the asset pricing side, the countercyclicality in the risk premium. The New Keynesian framework thus appears to play a crucial role in determining the effect of the EIS on macroeconomic dynamics and asset pricing variables.

\subsection{Preference shocks}

As disaster risk is captured by a shift in preferences, our effects resemble those from exogenous shocks to the discount rate.

The asset pricing literature argues that supply-driven shocks alone cannot account for the observed movements in asset prices and thus points out the needs for considering shocks to 'preference shocks' (Campbell and Ammer (1993), Cochrane (2011)). More generally, by changing the demand for assets, preference shocks have been sucessful in matching the equity premium, the bond term premium, and the weak correlation between stock returns and fundamentals by generating a good fit for risk-free rate variations independently of cash flows (see for instance the early work of Campbell (1986) and recent papers by Schorfheide et al. (2014) and Albuquerque et al. (2015)).

However, these models, just as Gourio (2012), generally consider a negative shock to the discount factor, i.e an increase in agents' impatience: they suddenly want to consume more and hold fewer assets. On the contrary, the New Keynesian literature generally studies the effects of positive preference shocks, i.e a decrease in agents' patience. This has been successful in some dimensions, for instance lately in making the zero lower bound (ZLB) on policy interest rates binding (see Eggertsson and Woodford (2003), Eggerston et al. (2014), and Erceg and Linde (2012)). An increase in the discount factor decreases agents' propensity to consume and puts downward pressure on real factor prices, real marginal cost and inflation. The real interest rate must diminish to reduce deflationary pressures. Empirically, variance decomposition shows that positive preference shocks is one of the main determinants of the nominal interest rate (Smets and Wouters (2003) and Ireland (2004)).

One of our contributions here is to conciliate the asset pricing partial equilibrium effects of a negative preference shock, by considering the exact same mechanism as in Gourio (2012), with the general equilibrium effects obtained with exogenous preference shocks in the New 
Keynesian literature. This is far from trivial as both literatures have found a recession and an increase in risk premia (or flight-to-quality) to be associated with opposite movements in the discount factor. Yet, we show here that Gourio's definition of the disaster risk can give responses compatible with the predictions for exogenous positive preference shocks whenever an EIS below unity and sticky prices are adopted. In line with the ZLB literature, we find that preference shifts lower interest rates on bonds, cause deflation and recession. ${ }^{27}$

\subsection{Uncertainty shocks and fat-tail events}

Another class of shocks related to ours is changes in aggregate uncertainty, or second-moment shocks. Shocks to the level of the probability of disaster considered here provide effects very comparable to volatility shocks in preferences, as in Basu and Bundick (2014). In that sense, disaster risk can be understood as a potential source of aggregate uncertainty. Bloom (2009) finds that an increase in uncertainty generates an immediate drop in output, as well as in labor and productivity as firms wait before hiring and reallocation from low to high productivity firms is impeded. In the medium term however, the economy bounces back as firms address their pent-up demand for labor and capital. With this respect, a disaster risk shock has a similar effect to uncertainty shock as it produces a short sharp recession followed by an "overshooting" in the recovery. This idea is supported empirically by Baker and Bloom (2013) who use rare events, such as natural disasters, terrorist attacks, political coups d'état and revolutions to instrument for changes in the level and volatility of stock-market returns. They argue that some shocks, like natural disasters, lead primarily to a change in stock-market levels (firstmoment shocks), while other shocks like coups d'état lead mainly to changes in stock-market volatility (second-moment shocks).

Finally, a related but slightly separated literature has considered 'disasters' as rare events stemming from non-Gaussian shock distributions. Cúrdia et al. (2014) and Chib and Ramamurthy (2014) show evidence that models with a multivariate $t$-distributed shock structure are favored by the data over standard Gaussian models. Auray et al (2012) show that limiting distributions of several aggregate macroeconomic time series, such as GDP, real wages and capital stock, exhibit fat tails if the returns to scale episodically increase. Andreasen (2012) studies rare disasters and uncertainty shocks, through skewed shock distributions, affect risk premia in a DSGE model. Weitzman (2012) also examines the effects of nonnormalities and rare disasters on risk premia. He finds that, with a higher probability weight on very bad outcomes, tail

\footnotetext{
${ }^{27}$ The only apparent difference with Christiano et al. (2011) concerns the response of investment. Given that capital accumulation is included in our model, a decrease in the real interest rate drives investment up following the shock. In a model extension, Christiano et al. (2011) also considers capital accumulation but because the ZLB prevents the nominal interest rate from declining following a preference shock, and deflation arrives, the real interest rate increases, such that investment naturally cannot rise. Our model does not impose such a constraint but it would be straightforward to do so. In that case, a fall in investment would deepen the recessionary effects of disaster risk.
} 
fattening reduces the magnitude of equity premium and riskfree rate puzzles. Finally, Wachter (2013) analyzes the effects of a time-varying probability of a consumption disaster and assumes that the conditional distribution of consumption growth becomes highly non-normal when a disaster is relatively likely.

\section{Conclusion}

This paper has developed a New Keynesian model featuring a small but time-varying probability of rare events à la Gourio (2012). The purpose was twofold. First, we aimed at conciliating the recessionary effects of an unexpected rise in disaster risk with a standard value of the elasticity of intertemporal of substitution. Indeed, we have first shown that Gourio (2012)'s flexible-price results hold if and only if the EIS is above unity. However, we then argued that the presence of sticky prices provides a solution by making the response of output primarily impacted by the response of consumption, instead of savings in real business cycle models.

Second, we aimed at conciliating the macroeconomic effects of the disaster risk with the preference shock literature. Indeed, under Gourio (2012)'s assumptions, the disaster risk is equivalent to a shift in the discount factor. However, recession is associated with agents becoming more impatient in Gourio (2012) but positive shocks to an exogenous discount factor, and thus agents becoming more patient in the New Keynesian literature (Smets and Wouters (2003), Christiano et al. (2011)). Here, we showed that Gourio (2012)'s model actually drives the agents to be more patient whenever the EIS is below unity. In that case and when combined with sticky prices, we can yet obtain a decrease in consumption, wage, and output, as well as deflation, and an increase in risk premia all together.

This model could easily be used for further research. In particular, it would be interesting to look at the optimal policies to be implement in the face of increased disaster risk. Also, it would be informative to study variations in the term premium due to the disaster risk, and how the short-term risk premium interacts with the long-term yield curve. The impact of unconventional monetary policies would then be particularly worth investigating.

\section{References}

[1] Rui Albuquerque, Martin Eichenbaum, Dimitris Papanikolaou, and Sergio Rebelo. Longrun Bulls and Bears. NBER Working Papers 20858, National Bureau of Economic Research, Inc, January 2015.

[2] Martin Andreasen. On the Effects of Rare Disasters and Uncertainty Shocks for Risk Premia in Non-Linear DSGE Models. Review of Economic Dynamics, 15(3):295-316, July 2012 . 
[3] Orazio P. Attanasio and Martin Browning. Consumption over the Life Cycle and over the Business Cycle. American Economic Review, 85(5):1118-37, December 1995.

[4] Stéphane Auray, Aurélien Eyquem, and Frédéric Jouneau-Sion. Modeling tails of aggregate economic processes in a stochastic growth model. Computational Statistics \& Data Analysis, 76(C):76-94, 2014.

[5] Scott R. Baker and Nicholas Bloom. Does Uncertainty Reduce Growth? Using Disasters as Natural Experiments. NBER Working Papers 19475, National Bureau of Economic Research, Inc, September 2013.

[6] Ravi Bansal, Dana Kiku, and Amir Yaron. An Empirical Evaluation of the Long-Run Risks Model for Asset Prices. Critical Finance Review, 1(1):183-221, January 2012.

[7] Ravi Bansal and Amir Yaron. Risks for the long run: A potential resolution of asset pricing puzzles. The Journal of Finance, 59(4):1481-1509, 2004.

[8] Robert J. Barro. Rare disasters and asset markets in the twentieth century. Quarterly Journal of Economics, 2006.

[9] Robert J. Barro and Tao Jin. On the size distribution of macroeconomic disasters. Econometrica, 79(5):1567-1589, 2011.

[10] Robert J. Barro and Jose F. Ursúa. Consumption disasters in the twentieth century. The American Economic Review, pages 58-63, 2008.

[11] Susanto Basu and Brent Bundick. Uncertainty shocks in a model of effective demand. Research Working Paper RWP 14-15, Federal Reserve Bank of Kansas City, November 2014.

[12] Tamim A Bayoumi. Financial Deregulation and Consumption in the United Kingdom. The Review of Economics and Statistics, 75(3):536-39, August 1993.

[13] Jason Beeler and John Y. Campbell. The Long-Run Risks Model and Aggregate Asset Prices: An Empirical Assessment. Critical Finance Review, 1(1):141-182, January 2012.

[14] Pierpaolo Benigno and Luigi Paciello. Monetary policy, doubts and asset prices. Journal of Monetary Economics, 64(C):85-98, 2014.

[15] Henk Berkman, Ben Jacobsen, and John B. Lee. Time-varying rare disaster risk and stock returns. Journal of Financial Economics, 101(2):313-332, August 2011.

[16] Nicholas Bloom. The Impact of Uncertainty Shocks. Econometrica, 77(3):623-685, 05 2009.

[17] Nicholas Bloom, Stephen Bond, and John Van Reenen. Uncertainty and Investment Dynamics. Review of Economic Studies, 74(2):391-415, 2007.

[18] Richard Blundell, Martin Browning, and Costas Meghir. Consumer Demand and the LifeCycle Allocation of Household Expenditures. Review of Economic Studies, 61(1):57-80, 
January 1994.

[19] Maren Brede. Disaster Risk in a New Keynesian Model. SFB 649 Discussion Papers SFB649DP2013-020, Sonderforschungsbereich 649, Humboldt University, Berlin, Germany, April 2013.

[20] Dario Caldara, Jesus Fernández-Villaverde, Juan Rubio-Ramírez, and Wen Yao. Computing DSGE Models with Recursive Preferences and Stochastic Volatility. Review of Economic Dynamics, 15(2):188-206, April 2012.

[21] John Y Campbell. Bond and Stock Returns in a Simple Exchange Model. The Quarterly Journal of Economics, 101(4):785-803, November 1986.

[22] John Y. Campbell and John Ammer. What Moves the Stock and Bond Markets? A Variance Decomposition for Long-Term Asset Returns. The Journal of Finance, 48(1):337, 1993.

[23] John Y. Campbell and John Cochrane. Force of Habit: A Consumption-Based Explanation of Aggregate Stock Market Behavior. Journal of Political Economy, 107(2):205-251, April 1999.

[24] John Y. Campbell and N. Gregory Mankiw. Consumption, Income and Interest Rates: Reinterpreting the Time Series Evidence. In NBER Macroeconomics Annual 1989, Volume 4, NBER Chapters, pages 185-246. National Bureau of Economic Research, Inc, May 1989.

[25] Siddhartha Chib and Srikanth Ramamurthy. DSGE Models with Student- t Errors. Econometric Reviews, 33(1-4):152-171, June 2014.

[26] Lawrence Christiano, Martin Eichenbaum, and Sergio Rebelo. When Is the Government Spending Multiplier Large? Journal of Political Economy, 119(1):78 - 121, 2011.

[27] John H Cochrane. Presidential address: Discount rates. The Journal of Finance, 66(4):1047-1108, 2011.

[28] Vasco Cúrdia, Marco Del Negro, and Daniel L. Greenwald. Rare Shocks, Great Recessions. Journal of Applied Econometrics, 29(7):1031-1052, November 2014.

[29] Gauti B. Eggertsson, Andrea Ferrero, and Andrea Raffo. Can structural reforms help europe? Journal of Monetary Economics, 61:2-22, 2014.

[30] Gauti B. Eggertsson and Michael Woodford. The Zero Bound on Interest Rates and Optimal Monetary Policy. Brookings Papers on Economic Activity, 34(1):139-235, 2003.

[31] Larry G. Epstein and Stanley E. Zin. Substitution, Risk Aversion, and the Temporal Behavior of Consumption and Asset Returns: A Theoretical Framework. Econometrica, 57(4):937-69, July 1989.

[32] Christopher J. Erceg and Jesper Linde. Fiscal Consolidation in an Open Economy. Amer- 
ican Economic Review, 102(3):186-91, May 2012.

[33] Xavier Gabaix. Variable Rare Disasters: A Tractable Theory of Ten Puzzles in Macrofinance. American Economic Review, 98(2):64-67, 2008.

[34] Xavier Gabaix. Disasterization: A Simple Way to Fix the Asset Pricing Properties of Macroeconomic Models. American Economic Review, 101(3):406-09, May 2011.

[35] Xavier Gabaix. Variable Rare Disasters: An Exactly Solved Framework for Ten Puzzles in Macro-Finance. The Quarterly Journal of Economics, 127(2):645-700, 2012.

[36] François Gourio. Disasters and recoveries. American Economic Review, 98(2):68-73, May 2008

[37] François Gourio. Disaster Risk and Business Cycles. American Economic Review, 102(6):2734-66, October 2012.

[38] François Gourio. Credit Risk and Disaster Risk. American Economic Journal: Macroeconomics, 5(3):1-34, July 2013.

[39] Robert E Hall. Intertemporal Substitution in Consumption. Journal of Political Economy, 96(2):339-57, April 1988.

[40] Tomas Havránek, Roman Horvath, Zuzana Irsova, and Marek Rusnak. Cross-country heterogeneity in intertemporal substitution. Journal of International Economics, 96(1):100$118,2015$.

[41] Abigail Hughes and Jumana Saleheen. UK labour productivity since the onset of the crisis ? an international and historical perspective. Bank of England Quarterly Bulletin, 52(2):138-146, 2012.

[42] Alfonso Irarrazabal and Juan Carlos Parra-Alvarez. Time-varying disaster risk models: An empirical assessment of the Rietz-Barro hypothesis. CREATES Research Papers 2015-08, School of Economics and Management, University of Aarhus, February 2015.

[43] Peter N. Ireland. Technology shocks in the new keynesian model. Review of Economics and Statistics, 86(4):923-936, 2004.

[44] Marlène Isoré and Urszula Szczerbowicz. Disaster Risk in a New Keynesian Model. Working Papers 2013-12, CEPII research center, April 2013.

[45] Sylvain Leduc and Zheng Liu. Uncertainty Shocks are Aggregate Demand Shocks. Working Paper Series 2012-10, Federal Reserve Bank of San Francisco, 2012.

[46] Hayne E. Leland. Saving and Uncertainty: The Precautionary Demand for Saving. The Quarterly Journal of Economics, 82(3):465-473, August 1968.

[47] Sydney Ludvigson. Consumption And Credit: A Model Of Time-Varying Liquidity Constraints. The Review of Economics and Statistics, 81(3):434-447, August 1999.

[48] Gregory N. Mankiw and Stephen P. Zeldes. The Consumption of Stockholders and 
Nonstockholders. Journal of Financial Economics, 29(1):97-112, 1991.

[49] Rajnish Mehra and Edward C. Prescott. The equity premium: A puzzle. Journal of monetary Economics, 15(2):145-161, 1985.

[50] Stephen Millard and Anamaria Nicolae. The effect of the financial crisis on TFP growth: a general equilibrium approach. Bank of England working papers 502, Bank of England, June 2014.

[51] Emi Nakamura, Jón Steinsson, Robert J. Barro, and José Ursúa. Crises and Recoveries in an Empirical Model of Consumption Disasters. American Economic Journal: Macroeconomics, 5(3):35-74, July 2013.

[52] Monika Piazzesi, Martin Schneider, and Selale Tuzel. Housing, consumption and asset pricing. Journal of Financial Economics, 83(3):531-569, March 2007.

[53] Thomas A. Rietz. The equity risk premium: a solution. Journal of Monetary Economics, 22(1):117-131, July 1988.

[54] Glenn D. Rudebusch and Eric T. Swanson. The Bond Premium in a DSGE Model with Long-Run Real and Nominal Risks. American Economic Journal: Macroeconomics, 4(1):105-43, January 2012.

[55] Agnar Sandmo. The Effect of Uncertainty on Saving Decisions. Review of Economic Studies, 37(3):353-60, July 1970.

[56] Frank Schorfheide, Dongho Song, and Amir Yaron. Identifying Long-Run Risks: A Bayesian Mixed-Frequency Approach. NBER Working Papers 20303, National Bureau of Economic Research, Inc, July 2014.

[57] Sang Byung Seo and Jessica A. Wachter. Option Prices in a Model with Stochastic Disaster Risk. NBER Working Papers 19611, National Bureau of Economic Research, Inc, November 2013.

[58] Frank Smets and Rafael Wouters. An Estimated Dynamic Stochastic General Equilibrium Model of the EURO Area. Journal of the European Economic Association, 1(5):11231175, 092003.

[59] Frank Smets and Rafael Wouters. Shocks and Frictions in US Business Cycles: A Bayesian DSGE Approach. American Economic Review, 97(3):586-606, 2007.

[60] Thomas D. Tallarini Jr. Risk-sensitive real business cycles. Journal of Monetary Economics, 45(3):507-532, June 2000.

[61] Jerry Tsai and Jessica A. Wachter. Disaster Risk and its Implications for Asset Pricing. NBER Working Papers 20926, National Bureau of Economic Research, Inc, February 2015.

[62] Annette Vissing-Jorgensen. Limited Asset Market Participation and the Elasticity of 
Intertemporal Substitution. Journal of Political Economy, 110(4):825-853, August 2002.

[63] Jessica A. Wachter. Can time-varying risk of rare disasters explain aggregate stock market volatility? The Journal of Finance, 68(3):987-1035, 2013.

[64] Philippe Weil. The equity premium puzzle and the risk-free rate puzzle. Journal of Monetary Economics, 24(3):401-421, November 1989.

[65] Philippe Weil. Nonexpected utility in macroeconomics. Quarterly Journal of Economics, 105(1):29-42, February 1990.

[66] Martin L. Weitzman. Rare Disasters, Tail-Hedged Investments, and Risk-Adjusted Discount Rates. NBER Working Papers 18496, National Bureau of Economic Research, Inc, October 2012.

[67] Wei Yang. Intertemporal Substitution and Equity Premium. Technical report, Review of Finance, forthcoming, 2015.

[68] Motohiro Yogo. Estimating the elasticity of intertemporal substitution when instruments are weak. Review of Economics and Statistics, 86(3):797-810, 2004. 


\section{Appendix}

\section{Households' problem with disaster risk}

\section{A. Capital accumulation with disaster risk}

Let us consider that the law of motion for capital is

$$
K_{t+1}=\left[\left(1-\delta_{0} u_{t}^{\eta}\right) K_{t}+S\left(\frac{I_{t}}{K_{t}}\right) K_{t}\right] e^{x_{t+1} \ln (1-\Delta)}
$$

where the depreciation rate of capital given by

$$
\delta_{t}=\delta_{0} u_{t}^{\eta}
$$

with $u$ the utilization rate of capital and $\eta$ a parameter, where $S($.$) is a capital adjustment$ cost function featuring the usual properties as given by

$$
S\left(\frac{I_{t}}{K_{t}}\right)=\frac{I_{t}}{K_{t}}-\frac{\tau}{2}\left(\frac{I_{t}}{K_{t}}-\frac{\bar{I}}{\bar{K}}\right)^{2}
$$

and where the last term expresses that capital accumulation is affected by the occurrence of a "disaster" captured by the indicator variable $x_{t+1}$. Specifically, if a disaster occurs, we have $x_{t+1}=1$, with a time-varying probability denoted $\theta_{t}$, a fraction $1-\Delta$ of capital is destroyed. Otherwise, $x_{t+1}=0$, and the law of motion is standard. Moreover, $\log \left(\theta_{t}\right)$ follows an AR1 process.

Following Gourio (2012)'s spirit, we assume that productivity is subject to the same disaster risk and follows

$$
\frac{z_{t+1}}{z_{t}}=e^{\mu+\varepsilon_{z, t+1}+x_{t+1} \ln (1-\Delta)}
$$

This allows to write a law of motion for the detrended capital stock as

$$
k_{t+1}=\frac{\left(1-\delta_{t}\right) k_{t}+S\left(\frac{i_{t}}{k_{t}}\right) k_{t}}{e^{\mu+\varepsilon_{z, t+1}}}
$$

where lower case letters denote the detrended variables $\left(k_{t}=K_{t} / z_{t}\right.$, etc). This way, the disaster event itself $x_{t+1}$ does not affect the detrended capital, while the disaster risk $\theta_{t}$ will however do (indirectly). 


\section{B. Bonds with disaster risk and the budget constraint}

In addition, households can also buy one-period bonds issued by a public authority. These assets are also subject to the same disaster risk, i.e

$$
B_{t+1}=\left[B_{t}\left(1+r_{t-1}\right)\right] e^{x_{t+1} \ln (1-\Delta)}
$$

or, reexpressed in detrended terms as $b_{t+1}=\frac{b_{t}\left(1+r_{t-1}\right)}{e^{\mu+\varepsilon_{z, t+1}}}$. The households' (detrended) budget constraint is thus given by

$$
\frac{w_{t}}{p_{t}} L_{t}+\frac{b_{t}\left(1+r_{t-1}\right)}{p_{t}}+\frac{P_{t}^{k}}{p_{t}} u_{t} k_{t}+\frac{D_{t}}{z_{t}}=i_{t}+c_{t}+\frac{b_{t+1}}{p_{t}} e^{\mu+\varepsilon_{z, t+1}}+\frac{T_{t}}{z_{t}}
$$

where $w$ stands for the (detrended) nominal wage rate, $p$ the good price, $P^{k}$ the (nominal) rental rate of capital received from the firms, $D$ the monopolistic firms' real profits, $T$ lumpsum taxes.

\section{Epstein-Zin preferences under disaster risk}

Epstein-Zin (1989) preferences are given by:

$$
\tilde{V}_{t}=\left[\left[C_{t}\left(1-L_{t}\right)^{\varpi}\right]^{1-\psi}+\beta_{0}\left(E_{t} \tilde{V}_{t+1}^{1-\gamma}\right)^{\frac{1-\psi}{1-\gamma}}\right]^{\frac{1}{1-\psi}}
$$

By setting $\tilde{V}_{t}=V_{t}^{\frac{1}{1-\psi}}$ and $\chi=1-\frac{1-\gamma}{1-\psi}$, we obtain

$$
V_{t}=\left[C_{t}\left(1-L_{t}\right)^{\varpi}\right]^{1-\psi}+\beta_{0}\left(E_{t} V_{t+1}^{1-\chi}\right)^{\frac{1}{1-\chi}}
$$

and finally defining $v_{t} \equiv \frac{V_{t}}{z_{t}^{1-\psi}}$, we get

$$
v_{t}=\left[c_{t}\left(1-L_{t}\right)^{\varpi}\right]^{1-\psi}+\frac{\beta_{0}}{z_{t}^{1-\psi}}\left(E_{t}\left(z_{t+1}^{1-\psi} v_{t+1}\right)^{1-\chi}\right)^{\frac{1}{1-\chi}}
$$

with $c_{t}=C_{t} / z_{t}$ stands for the detrended consumption. Since we have assumed that productivity evolves as $z_{t+1} / z_{t}=e^{\mu+\varepsilon_{z, t+1}+x_{t+1} \ln (1-\Delta)}$, we can rewrite the previous equation as

$$
\begin{gathered}
v_{t}=\left[c_{t}\left(1-L_{t}\right)^{\varpi}\right]^{1-\psi}+\frac{\beta_{0}}{z_{t}^{1-\psi}}\left(E_{t}\left(z_{t}^{(1-\psi)} e^{\left[\mu+\varepsilon_{z, t+1}+x_{t+1} \ln (1-\Delta)\right](1-\psi)} v_{t+1}\right)^{1-\chi}\right)^{\frac{1}{1-\chi}} \\
=\left[c_{t}\left(1-L_{t}\right)^{\varpi}\right]^{1-\psi}+\beta_{0}\left(E_{t} e^{\left[\mu+\varepsilon_{z, t+1}+x_{t+1} \ln (1-\Delta)\right](1-\psi)(1-\chi)} v_{t+1}^{1-\chi}\right)^{\frac{1}{1-\chi}}
\end{gathered}
$$


that can further be decomposed, in Gourio (2012)'s spirit, as

$$
v_{t}=\left[c_{t}\left(1-L_{t}\right)^{\varpi}\right]^{1-\psi}+\beta_{0} E_{t}\left[e^{(1-\gamma) x_{t+1} \ln (1-\Delta)}\right]^{\frac{1}{1-\chi}} e^{(1-\psi) \mu} E_{t}\left[e^{(1-\gamma) \varepsilon_{z, t+1}} v_{t+1}^{1-\chi}\right]^{\frac{1}{1-\chi}}
$$

with $(1-\gamma)=(1-\psi)(1-\chi)$ from earlier definition. Then, since there is a disaster $(x=1)$ with probability $\theta$ and no disaster $(x=0)$ with probability $(1-\theta)$, we can decompose in the expression above the term

$$
\beta_{0} E_{t}\left[e^{(1-\gamma) x_{t+1} \ln (1-\Delta)}\right]^{\frac{1}{1-\chi}}=\beta_{0}\left[\left(1-\theta_{t}\right)+\theta_{t} e^{(1-\gamma) \ln (1-\Delta)}\right]^{\frac{1}{1-\chi}}
$$

where the first expectation operator is conditional on the disaster risk and information at time $t$ whereas the second expectation operator is only conditional on information at time $t$.

Thus, redefining the discount factor as a function of the (time-varying) disaster risk (à la Gourio, 2012) as

$$
\beta(\theta) \equiv \beta_{0}\left[1-\theta_{t}+\theta_{t} e^{(1-\gamma) \ln (1-\Delta)}\right]^{\frac{1}{1-\chi}}
$$

our objective function can finally be rewritten as

$$
v_{t}=\left[c_{t}\left(1-L_{t}\right)^{\varpi}\right]^{1-\psi}+\beta\left(\theta_{t}\right) e^{(1-\psi) \mu}\left[E_{t} e^{(1-\gamma) \varepsilon_{z, t+1}} v_{t+1}^{1-\chi}\right]^{\frac{1}{1-\chi}}
$$

\section{Solving for the household's problem}

Households want to maximize (5) subject to (1)-(4) and (6). The Lagrangien for this problem can be written as

$$
\begin{aligned}
\mathcal{L}=\left[c_{t}\left(1-L_{t}\right)^{\varpi}\right]^{1-\psi}+\beta\left(\theta_{t}\right) e^{\mu(1-\psi)} & \left(E_{t} e^{\varepsilon_{z, t+1}(1-\gamma)} v_{t+1}^{(1-\chi)}\right)^{\frac{1}{1-\chi}} \\
+E_{t} \Lambda_{t}^{B}\left(\frac{w_{t}^{n o m}}{p_{t}} L_{t}-\frac{b_{t+1}}{p_{t}} e^{\mu+\varepsilon_{z, t+1}}\right. & \left.+\frac{b_{t}\left(1+r_{t-1}\right)}{p_{t}}+\frac{P_{t}^{k}}{p_{t}} u_{t} k_{t}+\frac{D_{t}}{z_{t}}-i_{t}-c_{t}-\frac{T_{t}}{z_{t}}\right) \\
& +E_{t} \Lambda_{t}^{C}\left[\left(1-\delta_{0} u_{t}^{\eta}\right) k_{t}+S\left(\frac{i_{t}}{k_{t}}\right) k_{t}-k_{t+1} e^{\mu+\varepsilon_{z, t+1}}\right]
\end{aligned}
$$

with $\delta_{t}=\delta_{0} u_{t}^{\eta}$ and $S\left(\frac{i_{t}}{k_{t}}\right)=\frac{i_{t}}{k_{t}}-\frac{\tau}{2}\left(\frac{i_{t}}{k_{t}}-\frac{\bar{i}}{\bar{k}}\right)^{2}$, and where $\Lambda_{t}^{B}$ and $\Lambda_{t}^{C}$ are the Lagrangian multipliers associated with the budget constraint and capital accumulation constraint respectively. The first-order conditions are thus

$$
\begin{gathered}
\left(c_{t}:\right)(1-\psi) c_{t}^{-\psi}\left(1-L_{t}\right)^{\varpi(1-\psi)}=\Lambda_{t}^{B} \\
\left(c_{t+1}:\right) \quad E_{t}\left[\beta\left(\theta_{t}\right) e^{(1-\psi) \mu} \frac{e^{(1-\gamma) \varepsilon_{z, t+1}} v_{t+1}^{-\chi}}{\left(E_{t} e^{(1-\gamma) \varepsilon_{z, t+1}} v_{t+1}^{1-\chi}\right)^{\frac{-\chi}{1-\chi}}}(1-\psi) c_{t+1}^{-\psi}\left(1-L_{t+1}\right)^{\varpi(1-\psi)}\right]=E_{t} \Lambda_{t+1}^{B}
\end{gathered}
$$




$$
\begin{gathered}
\left(L_{t}:\right) \quad \frac{1-L_{t}}{c_{t}}=\frac{\varpi}{w_{t}} \\
\left(b_{t+1}:\right) \quad \Lambda_{t}^{B} e^{\mu+\varepsilon_{z, t+1}}=E_{t}\left(\Lambda_{t+1}^{B} \frac{1+r_{t}}{1+\pi_{t+1}}\right) \\
\left(k_{t+1}:\right) \quad E_{t}\left\{\Lambda_{t+1}^{B} \frac{P_{t+1}^{k}}{p_{t+1}} u_{t+1}+\Lambda_{t+1}^{C}\left[1-\delta_{0} u_{t+1}^{\eta}+\tau \frac{i_{t+1}}{k_{t+1}}\left(\frac{i_{t+1}}{k_{t+1}}-\frac{\bar{i}}{\bar{k}}\right)\right.\right. \\
\left.\left.-\frac{\tau}{2}\left(\frac{i_{t+1}}{k_{t+1}}-\frac{\bar{i}}{\bar{k}}\right)^{2}\right]\right\}=\Lambda_{t}^{C} e^{\mu+\varepsilon_{z, t+1}} \\
\left(u_{t}:\right) \quad \Lambda_{t}^{B} \frac{P_{t}^{k}}{p_{t}}=\Lambda_{t}^{C} \delta_{0} \eta u_{t}^{\eta-1} \\
\left(i_{t}:\right) \quad \Lambda_{t}^{B}=\Lambda_{t}^{C}\left[1-\tau\left(\frac{i_{t}}{k_{t}}-\frac{\bar{i}}{\bar{k}}\right)\right]
\end{gathered}
$$

Finally, substituting out the Lagrange multipliers, we get the optimality conditions expressed in detrended terms.

\section{E. The stochastic discount factor}

The stochastic discount factor is defined as

$$
Q_{t, t+1}=\frac{\partial \tilde{V}_{t} / \partial C_{t+1}}{\partial \tilde{V}_{t} / \partial C_{t}}
$$

and, recalling that $\tilde{V}_{t}=V_{t}^{\frac{1}{1-\psi}}$ and $\chi=1-\frac{1-\gamma}{1-\psi}$, we get

$$
Q_{t, t+1}=\beta_{0}\left(\frac{C_{t+1}}{C_{t}}\right)^{-\psi}\left(\frac{1-L_{t+1}}{1-L_{t}}\right)^{\varpi(1-\psi)} \frac{V_{t+1}^{-\chi}}{\left(E_{t} V_{t+1}^{1-\chi}\right)^{\frac{-\chi}{1-\chi}}}
$$

Then, to further express it as a function of the detrended variables, let us use $v_{t} \equiv \frac{V_{t}}{z_{t}^{1-\psi}}$ and the expression above to get

$$
Q_{t, t+1}=\frac{z_{t}}{z_{t+1}}\left(\frac{c_{t+1}}{c_{t}}\right)^{-\psi}\left(\frac{1-L_{t+1}}{1-L_{t}}\right)^{\varpi(1-\psi)} \beta\left(\theta_{t}\right) e^{(1-\psi) \mu} \frac{e^{(1-\gamma) \varepsilon_{z, t+1}} v_{t+1}^{-\chi}}{\left[E_{t} e^{(1-\gamma) \varepsilon_{z, t+1}} v_{t+1}^{1-\chi}\right]^{\frac{-\chi}{1-\chi}}}
$$

Note that we cannot use this expression as such for using the perturbation methods since the term $\frac{z_{t}}{z_{t+1}}$ still contain the disaster variable $x$. However, recall the first-order condition on bonds as

$$
\frac{E_{t} \Lambda_{t+1}^{B}}{\Lambda_{t}^{B}}=e^{\mu+\varepsilon_{z, t+1}} \frac{E_{t}\left(1+\pi_{t+1}\right)}{1+r_{t}}
$$




$$
=E_{t}\left[\beta\left(\theta_{t}\right) e^{(1-\psi) \mu} \frac{e^{(1-\gamma) \varepsilon_{z, t+1}} v_{t+1}^{-\chi}}{\left(E_{t} e^{(1-\gamma) \varepsilon_{z, t+1}} v_{t+1}^{1-\chi}\right)^{\frac{-\chi}{1-\chi}}}\left(\frac{c_{t+1}}{c_{t}}\right)^{-\psi}\left(\frac{1-L_{t+1}}{1-L_{t}}\right)^{\varpi(1-\psi)}\right]
$$

Finally, 'detrending' the Lagrange multipliers, $\lambda_{t}^{B} \equiv \frac{\Lambda_{t}^{B}}{z_{t}}$, we get an equilibrium condition as

$$
\begin{gathered}
Q_{t, t+1}=\frac{z_{t}}{z_{t+1}} \frac{\Lambda_{t+1}^{B}}{\Lambda_{t}^{B}}=\frac{\lambda_{t+1}^{B}}{\lambda_{t}^{B}}, \quad \text { or } \\
\tilde{Q}_{t, t+1} \equiv Q_{t, t+1} \frac{z_{t+1}}{z_{t}}=\frac{\Lambda_{t+1}^{B}}{\Lambda_{t}^{B}}=e^{\mu+\varepsilon_{z, t+1}} \frac{1+\pi_{t+1}}{1+r_{t}}
\end{gathered}
$$

\section{F. The risk premium}

The standard asset pricing orthogonality condition reads as

$$
E_{t}\left[Q_{t, t+1} R_{t+1}^{i}\right]=1
$$

where $R^{i}$ is the real return on asset $i$. Thus, the riskfree rate, $R^{f}$, is

$$
E_{t}\left[Q_{t, t+1} R_{t+1}^{f}\right]=1
$$

Moreover, from the first-order condition on bonds, we know that

$$
E_{t}\left[\tilde{Q}_{t, t+1}\right]=E_{t}\left[Q_{t, t+1} \frac{z_{t+1}}{z_{t}}\right]=E_{t}\left[e^{\mu+\varepsilon_{z, t+1}} \frac{1+\pi_{t+1}}{1+r_{t}}\right]
$$

such that the (real) rate of return on capital can be written as

$$
R_{t+1}^{k, r e a l}=\frac{z_{t+1}}{z_{t}} \frac{1}{e^{\mu+\varepsilon_{z, t+1}}} \frac{1+r_{t}}{1+\pi_{t+1}}=e^{x_{t+1} \ln (1-\Delta)} \frac{1+r_{t}}{1+\pi_{t+1}}
$$

Further replaced into the (non detrended) condition on capital, we get

$$
\begin{gathered}
R_{t+1}^{k, \text { real }}=e^{x_{t+1} \ln (1-\Delta)}\left\{\frac{P_{t+1}^{k}}{p_{t+1}} \frac{u_{t+1}}{q_{t}}+\frac{q_{t+1}}{q_{t}}\left[1-\delta_{0} u_{t+1}^{\eta}+\tau \frac{i_{t+1}}{k_{t+1}}\left(\frac{i_{t+1}}{k_{t+1}}-\frac{\bar{i}}{\bar{k}}\right)\right.\right. \\
\left.\left.-\frac{\tau}{2}\left(\frac{i_{t+1}}{k_{t+1}}-\frac{\bar{i}}{\bar{k}}\right)^{2}\right]\right\}
\end{gathered}
$$

Finally, the risk premium is defined in gross terms as the ratio of the real return on capital to the riskfree rate, i.e $E_{t}\left(\right.$ Premium $\left._{t+1}\right) \equiv E_{t}\left(R_{t+1}^{k, r e a l} / R_{t+1}^{f}\right)$. 


\section{G. The role of the EIS on households' decisions}

\section{G.1. The response of the discount factor to the disaster risk}

The EIS is given by the following combination of parameters in our model

$$
E I S=\frac{1}{1-(1+\varpi)(1-\psi)}
$$

so that the time-varying discount factor (6) can be rewritten as

$$
\beta(\theta)=\beta_{0}\left[1-\theta_{t}\left(1-e^{(1-\gamma) \ln (1-\Delta)}\right)\right]^{\frac{1-1 / E I S}{(1-\gamma)(1+\varpi)}}
$$

Taking the derivate with respect to the probability of disaster gives

$$
\frac{\partial \beta(\theta)}{\partial \theta}=\beta_{0} \underbrace{\frac{1-1 / E I S}{(1-\gamma)(1+\varpi)}}_{A} \underbrace{\left[e^{(1-\gamma) \ln (1-\Delta)}-1\right]}_{B} \underbrace{\left[1-\theta_{t}\left(1-e^{(1-\gamma) \ln (1-\Delta)}\right)\right]^{\frac{1-1 / E I S}{(1-\gamma)(1+\varpi)}-1}}_{C}
$$

The sign of this expression crucially depends on the value of the EIS. Given $\varpi>0, \Delta>0$, $\theta>0, \beta_{0}>0$, we have:

- With EIS $<1$ and $\gamma>1, \mathrm{~A}>0, \mathrm{~B}>0, \mathrm{C}>0$, so $\frac{\partial \beta(\theta)}{\partial \theta}>0$;

- With EIS $<1$ and $0 \leq \gamma<1, \mathrm{~A}<0, \mathrm{~B}<0, \mathrm{C}>0$, so $\frac{\partial \beta(\theta)}{\partial \theta}>0$;

- With EIS $>1$ and $\gamma>1, \mathrm{~A}<0, \mathrm{~B}>0, \mathrm{C}>0$, so $\frac{\partial \beta(\theta)}{\partial \theta}<0$;

- With EIS $>1$ and $0 \leq \gamma<1, \mathrm{~A}>0, \mathrm{~B}<0, \mathrm{C}>0$, so $\frac{\partial \beta(\theta)}{\partial \theta}<0$;

- With $\lim _{E I S \rightarrow 1} \frac{\partial \beta(\theta)}{\partial \theta} \rightarrow 0$.

Overall, an increase in the probability of disaster thus makes agents more patient (higher $\beta(\theta)$ ) when the EIS is below unity, and inversely, more impatient (lower $\beta(\theta)$ ) when the EIS is above unity. This holds for all degrees of risk aversion (all values of $\gamma$ ), including risk neutrality.

\section{G.2. The response of the riskfree rate to the disaster risk (along the balanced growth path)}

Along the balanced growth path, the riskfree rate is given by

$$
R^{f}=\frac{\left[1-\theta\left(1-e^{(1-\gamma) \ln (1-\Delta)}\right)\right]^{\frac{\varpi(1-\gamma)+1 / E I S-\gamma}{(1+\varpi)(1-\gamma)}}}{\beta_{0} e^{-\mu \frac{\varpi+1 / E I S}{1+\varpi}}\left[1-\theta\left(1-e^{-\gamma \ln (1-\Delta)}\right)\right]}
$$

The derivative $\partial R^{f} / \partial \theta$ is always negative, i.e the riskfree rate decreases in the disaster risk for all values of the EIS and risk aversion. However, the magnitude of the slump is sensitive to the value of the EIS: the riskfree rate decreases more with the disaster risk for an EIS below 
unity than for an EIS above unity, given the degree of risk aversion (including risk neutrality). For instance, with the baseline calibration we find

- With EIS $=0.5$ and $\gamma=3.8, \frac{\partial R^{f}}{\partial \theta} \approx-0.666$;

- With EIS $=2$ and $\gamma=3.8, \frac{\partial R^{f}}{\partial \theta} \approx-0.504$;

- With EIS $=0.5$ and $\gamma=0.5, \frac{\partial R^{f}}{\partial \theta} \approx-0.324$;

- With EIS $=2$ and $\gamma=0.5, \frac{\partial R^{f}}{\partial \theta} \approx-0.217$;

- With EIS $=0.5$ and $\gamma=0, \frac{\partial R^{f}}{\partial \theta} \approx-0.291$;

- With EIS $=2$ and $\gamma=0, \frac{\partial R^{f}}{\partial \theta} \approx-0.190$

Note again that this is not a general equilibrium effect.

\section{G.3. The response of the return on capital to the disaster risk (along the balanced growth path)}

Along the balanced growth path, the return on capital is given by

$$
R^{k}=\frac{1-\theta\left(1-e^{\ln (1-\Delta)}\right)}{\beta_{0} e^{-\mu \frac{\varpi+1 / E I S}{1+\varpi}}\left[1-\theta\left(1-e^{(1-\gamma) \ln (1-\Delta)}\right)\right]^{\frac{1-1 / E I S}{(1-\gamma)(1+\varpi)}}}
$$

The derivative $\partial R^{k} / \partial \theta$ is also always negative, i.e the rate of return on capital decreases in the disaster risk. However, just as for the riskfree rate, the decrease is larger when the EIS is below unity (rather than above), for all values of risk aversion (including risk neutrality). For instance, we have

- With EIS $=0.5$ and $\gamma=3.8, \frac{\partial R^{k}}{\partial \theta} \approx-0.332$;

- With EIS $=2$ and $\gamma=3.8, \frac{\partial R^{k}}{\partial \theta} \approx-0.169$;

- With EIS $=0.5$ and $\gamma=0.5, \frac{\partial R^{k}}{\partial \theta} \approx-0.295$;

- With EIS $=2$ and $\gamma=0.5, \frac{\partial R^{k}}{\partial \theta} \approx-0.188$;

- With EIS $=0.5$ and $\gamma=0, \frac{\partial R^{k}}{\partial \theta} \approx-0.291$;

- With EIS $=2$ and $\gamma=0, \frac{\partial R^{k}}{\partial \theta} \approx-0.190$

\section{G.4. The response of the risk premium to the disaster risk (along the balanced growth path)}

Finally, along the balanced growth path, the risk premium is given by

$$
\text { Premium }=\frac{\left[1-\theta\left(1-e^{\ln (1-\Delta)}\right)\right]\left[1-\theta\left(1-e^{-\gamma \ln (1-\Delta)}\right)\right]}{1-\theta\left(1-e^{(1-\gamma) \ln (1-\Delta)}\right)}
$$

The derivative, calculated under our calibration values, gives 
- With $\gamma=3.8, \frac{\partial E\left(R^{k}\right) / R^{f}}{\partial \theta} \approx 0.333$;

- With $\gamma=0.5, \frac{\partial E\left(R^{k}\right) / R^{f}}{\partial \theta} \approx 0.029$;

- With $\gamma=0, \frac{\partial E\left(R^{k}\right) / R^{f}}{\partial \theta}=0$.

The risk premium reacts positively to the disaster risk, and the larger the risk aversion the larger its magnitude. It does not directly depend on the value of the EIS along the balanced growth path, in line with Gourio (2012). However, in general equilibrium, the EIS plays a qualitative role: the larger the EIS, the smaller the risk premium in response to the disaster risk shock (see the impulse response functions, comparing Figures 1 and 2 (flexible prices) on one hand, and Figures 3 and 4 (sticky prices) on the other hand).

\section{Firms' problem}

\section{A. Production aggregation}

The aggregate of intermediate goods is given by

$$
Y_{t}=\left(\int_{0}^{1} Y_{j, t}^{\frac{\nu-1}{\nu}} d j\right)^{\frac{\nu}{\nu-1}}
$$

so that the representative firm in the final sector maximizes profits as

$$
\max _{Y_{t, j}} p_{t}\left(\int_{0}^{1} Y_{j, t}^{\frac{\nu-1}{\nu}} d j\right)^{\frac{\nu}{\nu-1}}-\int_{0}^{1} p_{j, t} Y_{j, t} d j
$$

The first-order condition with respect to $Y_{t, j}$ yields a downward sloping demand curve for each intermediate good $j$ as

$$
Y_{j, t}=\left(\frac{p_{j, t}}{p_{t}}\right)^{-\nu} Y_{t}
$$

The nominal value of the final good is the sum of prices times quantities of intermediates

$$
p_{t} Y_{t}=\int_{0}^{1} p_{j, t} Y_{j, t} d j
$$

in which $Y_{t}$ is substituted to give the aggregate price index as

$$
p_{t}=\left(\int_{0}^{1} p_{j, t}^{1-\nu} d j\right)^{\frac{1}{1-\nu}}
$$

\section{B. Cost minimization}

Firms are price-takers in the input markets, facing (non-detrended) nominal wage $W_{t}^{\text {nom }}$ and capital rental rate $P_{t}^{k}$. They choose the optimal quantities of labor and capital given the input 
prices and subject to the restriction of producing at least as much as the intermediate good is demanded at the given price. The intra-temporal problem is thus

$$
\begin{array}{cc} 
& \min _{L_{j, t}, \tilde{K}_{j, t}} W_{t} L_{j, t}+P_{t}^{k} \tilde{K}_{j, t} \\
\text { s.t. } & \tilde{K}_{j, t}^{\alpha}\left(z_{t} L_{j, t}\right)^{1-\alpha} \geq\left(\frac{p_{j, t}}{p_{t}}\right)^{-\nu} Y_{t}
\end{array}
$$

The (detrended) first-order conditions are

$$
\begin{gathered}
\left(L_{j, t}:\right) \quad w_{t}=m c_{j, t}^{n o m}(1-\alpha)\left(\frac{\tilde{k}_{j, t}}{L_{j, t}}\right)^{\alpha} \\
\left(\tilde{K}_{j, t}:\right) \quad P_{t}^{k}=m c_{j, t}^{n o m} \alpha\left(\frac{\tilde{k}_{j, t}}{L_{j, t}}\right)^{\alpha-1}
\end{gathered}
$$

in which the Lagrange multiplier denoted $m c_{j, t}^{n o m}$ can be interpreted as the (nominal) marginal cost associated with an additional unit of capital or labor. Rearranging gives the optimal capital over labor ratio as

$$
\left(\frac{\tilde{k}_{j, t}}{L_{j, t}}\right)^{*}=\frac{w_{t}}{P_{t}^{k}} \frac{\alpha}{(1-\alpha)}
$$

in which none of the terms on the right hand side depends on $j$, and thus holds for all firms in equilibrium, i.e., $\frac{\tilde{k}_{t}}{L_{t}}=\frac{\tilde{k}_{j, t}}{L_{j, t}}$. Replacing in one of the first-order conditions above gives

$$
m c_{t}^{n o m *}=\left(\frac{P_{t}^{k}}{\alpha}\right)^{\alpha}\left(\frac{w_{t}}{1-\alpha}\right)^{1-\alpha}
$$

Reexpressing in real terms $m c_{t}^{*}=m c_{t}^{n o m *} / p_{t}$, we finally have

$$
m c_{t}^{*}=\left(\frac{P_{t}^{k, r e a l}}{\alpha}\right)^{\alpha}\left(\frac{w_{t}^{\text {real }}}{1-\alpha}\right)^{1-\alpha}
$$

where $P^{k, r e a l}$ and $w^{\text {real }}$ are the real capital rental rate and (detrended) wage.

\section{Profit maximization}

Let us now consider the pricing problem of a firm that gets to update its price in period $t$ and wants to maximize the present discounted value of future profits. The (nominal) profit flows read as

$$
p_{j, t} Y_{j, t}-W_{t} L_{j, t}-P_{j, t}^{k} \tilde{K}_{j, t}=\left(p_{j, t}-m c_{t}^{n o m}\right) Y_{j, t}
$$

which can be reexpressed in real terms as $\frac{p_{j, t}}{p_{t}} Y_{j, t}-m c_{t}^{*} Y_{j, t}$. These profit flows are discounted by both the stochastic discount factor, $Q_{t, t+s}$, and by the probability $\zeta^{s}$ that a price chosen at 
time $t$ is still in effect at time $s$. Finally, given $Y_{j, t}=\left(\frac{p_{j, t}}{p_{t}}\right)^{-\nu} Y_{t}$, the maximization problem is thus

$$
\max _{p_{j, t}} E_{t} \sum_{s=0}^{\infty}(\zeta)^{s} Q_{t+s}\left(\left(\frac{p_{j, t}}{p_{t+s}}\right)^{1-\nu} Y_{t+s}-m c_{t+s}^{*}\left(\frac{p_{j, t}}{p_{t+s}}\right)^{-\nu} Y_{t+s}\right)
$$

which can be further simplified, using $m c_{t}^{*}=\frac{m c_{t}^{n o m}}{p_{t}}$ and factorizing, as

$$
\max _{p_{j, t}} E_{t} \sum_{s=0}^{\infty}(\zeta)^{s} Q_{t+s} p_{t+s}^{\nu-1} Y_{t+s}\left(p_{j, t}^{1-\nu}-m c_{t}^{n o m} p_{j, t}^{-\nu}\right)
$$

The first-order condition is then

$$
E_{t} \sum_{s=0}^{\infty}(\zeta)^{s} Q_{t+s} p_{t+s}^{\nu-1} Y_{t+s}\left((1-\nu) p_{j, t}^{-\nu}+\nu m c_{t}^{n o m} p_{j, t}^{-\nu-1}\right)=0
$$

which simplifies as

$$
p_{j, t}^{*}=\frac{\nu}{\nu-1} E_{t} \frac{\sum_{s=0}^{\infty}(\zeta)^{s} Q_{t+s} p_{t+s}^{\nu} Y_{t+s} m c_{t+s}^{*}}{\sum_{s=0}^{\infty}(\zeta)^{s} Q_{t+s} p_{t+s}^{\nu-1} Y_{t+s}}
$$

Note that this optimal price depends on aggregate variables only, so that $p_{t}^{*}=p_{j, t}^{*}$. Expressed as a ratio over the current price, we thus have

$$
\frac{p_{t}^{*}}{p_{t}}=\frac{\nu}{\nu-1} E_{t} \frac{\sum_{s=0}^{\infty}(\zeta)^{s} Q_{t+s}\left(\frac{p_{t+s}}{p_{t}}\right)^{\nu} Y_{t+s} m c_{t+s}^{*}}{\sum_{s=0}^{\infty}(\zeta)^{s} Q_{t+s}\left(\frac{p_{t+s}}{p_{t}}\right)^{\nu-1} Y_{t+s}}
$$

which can be written recursively as

$$
\begin{gathered}
\frac{p_{t}^{*}}{p_{t}}=\frac{\nu}{\nu-1} E_{t} \frac{\Xi_{1_{t}}}{\Xi_{2_{t}}} \text { with } \\
\Xi_{1_{t}}=Y_{t} m c_{t}^{*}+\zeta E_{t} Q_{t, t+1}\left(\frac{p_{t+1}}{p_{t}}\right)^{\nu} \Xi_{1_{t+1}} \\
\Xi_{2_{t}}=Y_{t}+\zeta E_{t} Q_{t, t+1}\left(\frac{p_{t+1}}{p_{t}}\right)^{\nu-1} \Xi_{2_{t+1}}
\end{gathered}
$$

Replacing $Q_{t, t+1} \equiv \tilde{Q}_{t, t+1} \frac{z_{t}}{z_{t+1}}$, and detrending, these are simplified as

$$
\begin{gathered}
\tilde{\Xi}_{1_{t}}=y_{t} m c_{t}^{*}+\zeta E_{t} \tilde{Q}_{t, t+1}\left(\frac{p_{t+1}}{p_{t}}\right)^{\nu} \tilde{\Xi}_{1_{t+1}} \\
\tilde{\Xi}_{2_{t}}=y_{t}+\zeta E_{t} \tilde{Q}_{t, t+1}\left(\frac{p_{t+1}}{p_{t}}\right)^{\nu-1} \tilde{\Xi}_{2_{t+1}}
\end{gathered}
$$

where $\tilde{\Xi}_{t} \equiv \Xi_{t} / z_{t}$, the detrended variable. 


\section{Aggregation}

\section{A. Bonds market}

Market-clearing requires that the public debt equals the quantity of bonds at each time, Debt $_{t}=B_{t}$, and is thus symmetrically affected by disasters. Moreover, we assume that the public budget has to be balanced every period, i.e the sum of tax revenues and new debt insuance to equal the current debt insuance to be repaid with interest rates (as for the non-disaster part), i.e

$$
T_{t} p_{t}+B_{t+1}=\left[B_{t}\left(1+r_{t-1}\right)\right] e^{x_{t+1} \ln (1-\Delta)}
$$

or, in detrended terms,

$$
\frac{T_{t}}{z_{t}}+\frac{b_{t+1}}{p_{t}}=\frac{b_{t}\left(1+r_{t-1}\right)}{p_{t} e^{\mu+\varepsilon_{z, t+1}}}
$$

\section{B. Aggregate demand}

Replacing the tax level above into the household's budget constraint gives

$$
c_{t}+i_{t}+\left(\frac{b_{t}\left(1+r_{t-1}\right)}{p_{t} e^{\mu+\varepsilon_{z, t+1}}}-\frac{b_{t+1}}{p_{t}}\right)=w_{t}^{r e a l} L_{t}+\left(\frac{b_{t}\left(1+r_{t-1}\right)}{p_{t} e^{\mu+\varepsilon_{z, t+1}}}-\frac{b_{t+1}}{p_{t}}\right)+P_{t}^{k, r e a l} u_{t} k_{t}+\frac{D_{t}}{z_{t}}
$$

which just simplifies as

$$
c_{t}+i_{t}=w_{t}^{r e a l} L_{t}+P_{t}^{k, r e a l} \tilde{k}_{t}+\frac{D_{t}}{z_{t}}
$$

i.e, in non-detrended terms, as

$$
C_{t}+I_{t}=W_{t}^{\text {real }} L_{t}+P_{t}^{k, \text { real }} \tilde{K}_{t}+D_{t}
$$

where we now have to verify that the RHS is equal to $Y_{t}$. Total dividends (or profits) $D_{t}$ must be equal to the sum of dividends (or profits) from intermediate good firms, i.e

$$
D_{t}=\int_{0}^{1} D_{j, t} d j
$$

The (real) dividends (or profits) from intermediate good firms $j$ are given by

$$
D_{j, t}=\frac{p_{j, t}}{p_{t}} Y_{j, t}-W_{t}^{\text {real }} L_{j, t}-P_{t}^{k, r e a l} \tilde{K}_{j, t}
$$

Substituting $Y_{j, t}$, we have

$$
D_{j, t}=\left(\frac{p_{j, t}}{p_{t}}\right)^{1-\nu} Y_{t}-W_{t}^{r e a l} L_{j, t}-P_{t}^{k, \text { real }} \tilde{K}_{j, t}
$$


Therefore, knowing that $D_{t(\text { real })}=\int_{0}^{1} D_{j, t(r e a l)} d j$, we get

$$
\begin{array}{r}
D_{t}=\int_{0}^{1}\left(\left(\frac{p_{j, t}}{p_{t}}\right)^{1-\nu} Y_{t}-W_{t}^{r e a l} L_{j, t}-P_{t}^{k, \text { real }} \tilde{K}_{j, t}\right) d j=\int_{0}^{1}\left(\frac{p_{j, t}}{p_{t}}\right)^{1-\nu} Y_{t} d j \\
-\int_{0}^{1} W_{t}^{r e a l} L_{j, t} d j-\int_{0}^{1} P_{t}^{k, r e a l} \tilde{K}_{j, t} d j \\
D_{t}=\int_{0}^{1}\left(\left(\frac{p_{j, t}}{p_{t}}\right)^{1-\nu} Y_{t}-W_{t}^{\text {real }} L_{j, t}-P_{t}^{k, \text { real }} \tilde{K}_{j, t}\right) d j=Y_{t} \frac{1}{p_{t}^{1-\nu}} \int_{0}^{1}\left(p_{j, t}\right)^{1-\nu} d j \\
-W_{t}^{\text {real }} \int_{0}^{1} L_{j, t} d j-P_{t}^{k, r e a l} \int_{0}^{1} \tilde{K}_{j, t} d j
\end{array}
$$

Given that $(i)$ the aggregate price level is $p_{t}^{1-\nu}=\int_{0}^{1} p_{j, t}^{1-\nu} d j$, (ii) aggregate labor demand must equal supply, i.e $\int_{0}^{1} L_{j, t} d j=L_{t}$, and ( $\left.i i i\right)$ aggregate supply of capital services must equal demand $\int_{0}^{1} \tilde{K}_{j, t} d j=\tilde{K}_{t}$, the aggregate (real) dividend (or profit) is

$$
D_{t}=Y_{t}-W_{t}^{\text {real }} L_{t}-P_{t}^{k, r e a l} \tilde{K}_{t}
$$

Replaced into the household's budget constraint, this finally gives the aggregate accounting identity as

$$
Y_{t}=C_{t}+I_{t}
$$

or in detrended terms

$$
y_{t}=c_{t}+i_{t}
$$

\section{Inflation}

Firms have a probability $1-\zeta$ of getting to update their price each period. Since there are an infinite number of firms, there is also the exact fraction $1-\zeta$ of total firms who adjust their prices and the fraction $\zeta$ who stay with the previous period price. Moreover, since there is a random sampling from the entire distribution of firm prices, the distribution of any subset of firm prices is similar to the entire distribution. Therefore, the aggregate price index, $p_{t}^{1-\nu}=\int_{0}^{1} p_{j, t}^{1-\nu} d j$, is rewritten as

$$
p_{t}^{1-\nu}=\int_{0}^{1-\zeta} p_{t}^{* 1-\nu} d j+\int_{1-\zeta}^{1} p_{j, t-1}^{1-\nu} d j
$$

which simplifies as

$$
p_{t}^{1-\nu}=(1-\zeta) p_{t}^{* 1-\nu}+\zeta p_{t-1}^{1-\nu}
$$


Let us divide both sides of the equation by $p_{t-1}^{1-\nu}$

$$
\left(\frac{p_{t}}{p_{t-1}}\right)^{1-\nu}=(1-\zeta)\left(\frac{p_{t}^{*}}{p_{t-1}}\right)^{1-\nu}+\zeta\left(\frac{p_{t-1}}{p_{t-1}}\right)^{1-\nu}
$$

and define the gross inflation rate as

$$
1+\pi_{t} \equiv \frac{p_{t}}{p_{t-1}}
$$

and the gross reset inflation rate as

$$
1+\pi_{t}^{*} \equiv \frac{p_{t}^{*}}{p_{t-1}}
$$

we get

$$
\left(1+\pi_{t}\right)^{1-\nu}=(1-\zeta)\left(1+\pi_{t}^{*}\right)^{1-\nu}+\zeta
$$

Finally, since we know that

$$
\frac{p_{t}^{*}}{p_{t}}=\frac{\nu}{\nu-1} E_{t} \frac{\Xi_{1_{t}}}{\Xi_{2_{t}}}
$$

we have the reset inflation rate as

$$
\left(1+\pi_{t}^{*}\right)=\left(1+\pi_{t}\right) \frac{\nu}{\nu-1} E_{t} \frac{\Xi_{1_{t}}}{\Xi_{2_{t}}}
$$

with the expressions given previously for $\Xi_{1}$ and $\Xi_{2}$ (see Appendix B.3), or equivalently with the detrended terms as

$$
\left(1+\pi_{t}^{*}\right)=\left(1+\pi_{t}\right) \frac{\nu}{\nu-1} E_{t} \frac{\tilde{\Xi}_{1_{t}}}{\tilde{\Xi}_{2_{t}}}
$$

\section{Aggregate supply}

We know that the demand to individual firm $j$ is given by

$$
Y_{j, t}=\left(\frac{p_{j, t}}{p_{t}}\right)^{-\nu} Y_{t}
$$

and that firm $j$ hires labor and capital in the same proportion than the aggregate capital to labor ratio (common factor markets). Hence, substituting in the production function for the intermediate good $j$ we get

$$
\left(\frac{\tilde{K}_{t}}{z_{t} L_{t}}\right)^{\alpha} z_{t} L_{j, t}=\left(\frac{p_{j, t}}{p_{t}}\right)^{-\nu} Y_{t}
$$


which can be rewritten with detrended variables as

$$
\left(\frac{\tilde{k}_{t}}{L_{t}}\right)^{\alpha} L_{j, t}=\left(\frac{p_{j, t}}{p_{t}}\right)^{-\nu} y_{t}
$$

Then, summing up across the intermediate firms gives

$$
\left(\frac{\tilde{k}_{t}}{L_{t}}\right)^{\alpha} \int_{0}^{1} L_{j, t} d j=y_{t} \int_{0}^{1}\left(\frac{p_{j, t}}{p_{t}}\right)^{-\nu} d j
$$

Given that aggregate labor demand and supply must equal, i.e $\int_{0}^{1} L_{j, t} d j=L_{t}$, we have

$$
\int_{0}^{1}\left(\frac{p_{j, t}}{p_{t}}\right)^{-\nu} d j y_{t}=\tilde{k}_{t}^{\alpha} L_{t}^{1-\alpha}
$$

Thus, the aggregate production function can be written as

$$
y_{t}=\frac{\tilde{k}_{t}^{\alpha} L_{t}^{1-\alpha}}{\Omega_{t}}
$$

where $\Omega_{t}=\int_{0}^{1}\left(\frac{p_{j, t}}{p_{t}}\right)^{-\nu} d j$ measures a distortion introduced by the dispersion in relative prices. ${ }^{28}$ In order to express $\Omega_{t}$ in aggregate terms, let decompose it according to the Calvo pricing assumption again, so that

$$
\begin{gathered}
\Omega_{t}=\int_{0}^{1}\left(\frac{p_{j, t}}{p_{t}}\right)^{-\nu} d j=p_{t}^{\nu} \int_{0}^{1} p_{j, t}^{-\nu} \\
p_{t}^{\nu} \int_{0}^{1} p_{j, t}^{-\nu}=p_{t}^{\nu}\left(\int_{0}^{1-\zeta} p_{t}^{*-\nu} d j+\int_{1-\zeta}^{1} p_{j, t-1}^{-\nu} d j\right) \\
p_{t}^{\nu} \int_{0}^{1} p_{j, t}^{-\nu}=p_{t}^{\nu}(1-\zeta) p_{t}^{*-\nu}+p_{t}^{\nu} \int_{1-\zeta}^{1} p_{j, t-1}^{-\nu} d j \\
p_{t}^{\nu} \int_{0}^{1} p_{j, t}^{-\nu}=(1-\zeta)\left(\frac{p_{t}^{*}}{p_{t}}\right)^{-\nu}+p_{t}^{\nu} \int_{1-\zeta}^{1} p_{j, t-1}^{-\nu} d j \\
p_{t}^{\nu} \int_{0}^{1} p_{j, t}^{-\nu}=(1-\zeta)\left(\frac{p_{t}^{*}}{p_{t-1}}\right)^{-\nu}\left(\frac{p_{t-1}}{p_{t}}\right)^{-\nu}+p_{t}^{\nu} \int_{1-\zeta}^{1} p_{j, t-1}^{-\nu} d j \\
p_{t}^{\nu} \int_{0}^{1} p_{j, t}^{-\nu}=(1-\zeta)\left(1+\pi_{t}^{*}\right)^{-\nu}\left(1+\pi_{t}\right)^{\nu}+p_{t-1}^{-\nu} p_{t}^{\nu} \int_{1-\zeta}^{1}\left(\frac{p_{j, t-1}}{p_{t-1}}\right)^{-\nu} d j
\end{gathered}
$$

Given random sampling and the fact that there is a continuum of firms

$$
\Omega_{t}=(1-\zeta)\left(1+\pi_{t}^{*}\right)^{-\nu}\left(1+\pi_{t}\right)^{\nu}+\zeta\left(1+\pi_{t}\right)^{\nu} \Omega_{t-1}
$$

\footnotetext{
${ }^{28}$ This distortion is not the one associated with the monopoly power of firms but an additional one that arises from the relative price fluctuations due to prie stickiness.
} 


\section{Full set of equilibrium conditions}

Households' optimality conditions:

$$
\begin{aligned}
& \tilde{Q}_{t, t+1}=\left(\frac{c_{t+1}}{c_{t}}\right)^{-\psi}\left(\frac{1-L_{t+1}}{1-L_{t}}\right)^{\varpi(1-\psi)} \beta\left(\theta_{t}\right) e^{(1-\psi) \mu} \frac{e^{(1-\gamma) \varepsilon_{z, t+1}} v_{t+1}^{-\chi}}{E_{t}\left[e^{(1-\gamma) \varepsilon_{z, t+1}} v_{t+1}^{1-\chi}\right]^{\frac{-\chi}{1-\chi}}} \\
& \frac{1-L_{t}}{c_{t}}=\frac{\varpi}{w_{t}^{\text {real }}} \\
& \frac{E_{t}\left[1+\pi_{t+1}\right]}{1+r_{t}} e^{\mu+\varepsilon_{z, t+1}}=E_{t} \tilde{Q}_{t, t+1} \\
& E_{t} \tilde{Q}_{t, t+1} P_{t+1}^{k, r e a l}\left\{u_{t+1}+\frac{1}{\delta_{0} \eta u_{t+1}^{\eta-1}}\left[1-\delta_{0} u_{t+1}^{\eta}+\tau \frac{i_{t+1}}{k_{t+1}}\left(\frac{i_{t+1}}{k_{t+1}}-\frac{\bar{i}}{\bar{k}}\right)\right.\right. \\
& \left.\left.-\frac{\tau}{2}\left(\frac{i_{t+1}}{k_{t+1}}-\frac{\bar{i}}{\bar{k}}\right)^{2}\right]\right\}=\frac{P_{t}^{k, r e a l}}{\delta_{0} \eta u_{t}^{\eta-1}} e^{\mu+\varepsilon_{z, t+1}} \\
& \frac{\delta_{0} \eta u_{t}^{\eta-1}}{P_{t}^{k, r e a l}}=1-\tau\left(\frac{i_{t}}{k_{t}}-\frac{\bar{i}}{\bar{k}}\right)
\end{aligned}
$$

Households' constraints

$$
\begin{gathered}
v_{t}=\left[c_{t}\left(1-L_{t}\right)^{\varpi}\right]^{1-\psi}+\beta\left(\theta_{t}\right) e^{(1-\psi) \mu} E_{t}\left[e^{(1-\psi)(1-\chi) \varepsilon_{z, t+1}} v_{t+1}^{1-\chi}\right]^{\frac{1}{1-\chi}} \\
k_{t+1}=\frac{\left(1-\delta_{t}\right) k_{t}+S\left(\frac{i_{t}}{k_{t}}\right) k_{t}}{e^{\mu+\varepsilon_{z, t+1}}}
\end{gathered}
$$

Processus for the disaster risk

$$
\log \theta_{t}=\left(1-\rho_{\theta}\right) \log \bar{\theta}+\rho_{\theta} \log \theta_{t-1}+\sigma_{\theta} \varepsilon_{\theta_{t}}
$$

Time-varying discount factor

$$
\beta(\theta)=\beta_{0}\left[1-\theta_{t}+\theta_{t} e^{(1-\gamma) \ln (1-\Delta)}\right]^{\frac{1}{1-\chi}}
$$


Tobin's q

$$
q_{t}=\frac{1}{1-\tau\left(\frac{i_{t}}{k_{t}}-\overline{\bar{i}}\right)}
$$

Asset pricing

$$
\begin{gathered}
E_{t} Q_{t, t+1}=\frac{E_{t}\left(1+\pi_{t+1}\right)}{1+r_{t}} \frac{1}{1-\theta_{t} \Delta} \\
E_{t}\left[Q_{t, t+1} R_{t+1}^{f}\right]=1 \\
E_{t} R_{t+1}^{k, \text { real }}=\left(1-\theta_{t} \Delta\right) \frac{1+r_{t}}{E_{t}\left(1+\pi_{t+1}\right)} \\
E_{t}\left(\text { Premium }_{t+1}\right)=\frac{E_{t} R_{t+1}^{k, r e a l}}{R_{t+1}^{f}}
\end{gathered}
$$

Firms' constraints

$$
\begin{aligned}
& y_{t}=\frac{\tilde{k}^{\alpha} L_{t}^{1-\alpha}}{\Omega_{t}} \\
& \tilde{k}_{t}=u_{t} k_{t} \\
& w_{t}^{r e a l}=m c_{t}^{*}(1-\alpha)\left(\frac{\tilde{k}_{t}}{L_{t}}\right)^{\alpha} \\
& P_{t}^{k, r e a l}=m c_{t}^{*} \alpha\left(\frac{\tilde{k}_{t}}{L_{t}}\right)^{\alpha-1} \\
& \left(1+\pi_{t}^{*}\right)=\left(1+\pi_{t}\right) \frac{\nu}{\nu-1} E_{t} \frac{\tilde{\Xi}_{1_{t}}}{\tilde{\Xi}_{2_{t}}} \\
& \tilde{\Xi}_{1_{t}}=y_{t} m c_{t}^{*}+\zeta E_{t} \tilde{Q}_{t, t+1} \tilde{\Xi}_{1_{t+1}}\left(1+\pi_{t+1}\right)^{\nu} \\
& \tilde{\Xi}_{2_{t}}=y_{t}+\zeta E_{t} \tilde{Q}_{t, t+1} \tilde{\Xi}_{2_{t+1}}\left(1+\pi_{t+1}\right)^{\nu-1}
\end{aligned}
$$


Price distorsion:

$$
\Omega_{t}=(1-\zeta)\left(1+\pi_{t}^{*}\right)^{-\nu}\left(1+\pi_{t}\right)^{\nu}+\zeta\left(1+\pi_{t}\right)^{\nu} \Omega_{t-1}
$$

Price index:

$$
\left(1+\pi_{t}\right)^{1-\nu}=(1-\zeta)\left(1+\pi_{t}^{*}\right)^{1-\nu}+\zeta
$$

Taylor rule:

$$
r_{t}=\rho_{r} r_{t-1}+\left(1-\rho_{r}\right)\left[\Phi_{\pi}\left(\pi_{t}-\bar{\pi}\right)+\Phi_{Y}\left(y_{t}-y^{*}\right)+r^{*}\right]
$$

Aggregate resource constraint:

$$
y_{t}=c_{t}+i_{t}
$$

This is a system of 25 equations in 25 unknowns: $\left\{y, c, i, L, k, \tilde{k}, u, \beta, q, \theta, w^{\text {real }}, P^{k, \text { real }}, \tilde{Q}, Q\right.$, $R^{k, r e a l}, R^{f}$, Premium, $\left.\Omega, \pi, \pi^{*}, \tilde{\Xi}_{1}, \tilde{\Xi}_{2}, m c^{*}, v, r\right\}$. We solve for the steady-state and then use Dynare to simulate the responses to the disaster risk shock with a third-order approximation (unless otherwise specified). 